\title{
RESEARCH
}

Open Access

\section{TREM2 Alzheimer's variant R47H causes similar transcriptional dysregulation to knockout, yet only subtle functional phenotypes in human iPSC-derived macrophages}

Hazel Hall-Roberts ${ }^{1,2^{*}}$ (D), Devika Agarwal ${ }^{2,3}$, Juliane Obst ${ }^{2}$, Thomas B. Smith², Jimena Monzón-Sandoval4, Elena Di Daniel ${ }^{2}$, Caleb Webber ${ }^{4}$, William S. James ${ }^{1}$, Emma Mead ${ }^{2}$, John B. Davis ${ }^{2}$ and Sally A. Cowley ${ }^{1 *}$

\begin{abstract}
Background: TREM2 is a microglial cell surface receptor, with risk mutations linked to Alzheimer's disease (AD), including R47H. TREM2 signalling via SYK aids phagocytosis, chemotaxis, survival, and changes to microglial activation state. In AD mouse models, knockout (KO) of TREM2 impairs microglial clustering around amyloid and prevents microglial activation. The R47H mutation is proposed to reduce TREM2 ligand binding. We investigated cell phenotypes of the R47H mutant and TREM2 KO in a model of human microglia, and compared their transcriptional signatures, to determine the mechanism by which R47H TREM2 disrupts function.
\end{abstract}

Methods: We generated human microglia-like iPSC-macrophages (pMac) from isogenic induced pluripotent stem cell (iPSC) lines, with homozygous R47H mutation or TREM2 knockout (KO). We firstly validated the effect of the R47H mutant on TREM2 surface and subcellular localization in pMac. To assess microglial phenotypic function, we measured phagocytosis of dead neurons, cell morphology, directed migration, survival, and LPS-induced inflammation. We performed bulk RNA-seq, comparing significant differentially expressed genes (DEGs; $p<0.05$ ) between the R47H and KO versus WT, and bioinformatically predicted potential upstream regulators of TREM2mediated gene expression.

\footnotetext{
*Correspondence: hazel.hall-roberts@path.ox.ac.uk;

sally.cowley@path.ox.ac.uk

${ }^{1}$ James Martin Stem Cell Facility, Sir William Dunn School of Pathology, University of Oxford, Oxford OX1 3RE, UK

Full list of author information is available at the end of the article
}

(c) The Author(s). 2020 Open Access This article is licensed under a Creative Commons Attribution 4.0 International License, which permits use, sharing, adaptation, distribution and reproduction in any medium or format, as long as you give appropriate credit to the original author(s) and the source, provide a link to the Creative Commons licence, and indicate if changes were made. The images or other third party material in this article are included in the article's Creative Commons. licence, unless indicated otherwise in a credit line to the material. If material is not included in the article's Creative Commons licence and your intended use is not permitted by statutory regulation or exceeds the permitted use, you will need to obtain permission directly from the copyright holder. To view a copy of this licence, visit http://creativecommons.org/licenses/by/4.0/ The Creative Commons Public Domain Dedication waiver (http://creativecommons.org/publicdomain/zero/1.0/) applies to the data made available in this article, unless otherwise stated in a credit line to the data. 
(Continued from previous page)

Results: R47H modified surface expression and shedding of TREM2, but did not impair TREM2-mediated signalling, or gross phenotypes that were dysregulated in the TREM2 KO (phagocytosis, motility, survival). However, altered gene expression in the R47H TREM2 pMac overlapped by 90\% with the TREM2 KO and was characterised by dysregulation of genes involved with immunity, proliferation, activation, chemotaxis, and adhesion. Downregulated mediators of ECM adhesion included the vitronectin receptor aV 33 , and consequently, R47H TREM2 pMac adhered weakly to vitronectin compared with WT pMac. To counteract these transcriptional defects, we investigated TGF $\beta 1$, as a candidate upstream regulator. TGF $\beta 1$ failed to rescue vitronectin adhesion of pMac, although it improved aV $\beta 3$ expression.

Conclusions: The R47H mutation is not sufficient to cause gross phenotypic defects of human pMac under standard culture conditions. However, overlapping transcriptional defects with TREM2 KO supports the hypothesised partial loss-of-function effects of the R47H mutation. Furthermore, transcriptomics can guide us to more subtle phenotypic defects in the $\mathrm{R} 47 \mathrm{H}$ cells, such as reduced cell adhesion, and can be used to predict targets for therapeutic intervention.

Keywords: TREM2, R47H, Alzheimer's disease, iPSC, Human pluripotent stem cells, Macrophages, Microglia, Phagocytosis, Inflammation, Synaptosome

\section{Background}

Microglia are strongly implicated in the pathogenesis of late-onset Alzheimer's disease (LOAD). LOAD risk genes, identified by genome-wide association studies (GWAS), include TREM2, PLCG2, INPP5D, and APOE, the protein products of which share common signalling pathways in microglia $[1,2]$. Furthermore, non-coding LOAD risk variants are largely confined to microgliaspecific enhancer regions of the genome [3]. "Disease-associated" microglia have been identified in multiple mouse neurodegenerative disease models, which have a common transcriptional signature that is largely dependent on expression of Triggering Receptor Expressed in Myeloid cells 2 (TREM2) [4].

TREM2 is a myeloid cell surface receptor and requires the co-receptor DNAX-Activation Protein 12 (DAP12/ TYROBP) for signal transduction. TREM2-DAP12 receptor activation causes activation of spleen-associated tyrosine kinase (SYK). SYK phosphorylates and activates PI3K and PLC $\gamma 2$, inducing multiple downstream signalling events, resulting in intracellular calcium flux, actin mobilisation, and Akt and ERK activation [5]. TREM2 signalling ultimately regulates many major microglial functions, including phagocytosis [6], chemotaxis [7], survival and proliferation [8, 9], autophagy [10], lipid metabolism [11], and proinflammatory cytokine production [12]. TREM2 has a broad-specificity ligand-binding domain with minor preference for anionic substrates; therefore, it behaves like a scavenger receptor with a long list of putative ligands: various phospholipids and sphingomyelin [13], lipidated apolipoproteins including ApoE [14], bacterial lipopolysaccharides [15], nucleic acids [16], and oligomeric amyloid- $\beta$ [17].

Nasu-Hakola disease (NHD), a rare genetic disease presenting with early-onset dementia, is linked to mutations in TREM2 that prevent surface expression of mature protein. In contrast, two confirmed Alzheimer's disease (AD) risk-modifying mutations of TREM2, $\mathrm{R} 47 \mathrm{H}$ and $\mathrm{R} 62 \mathrm{H}$, occur within the ligand-binding domain of the protein and permit maturation and cell surface expression $[18,19]$. R47H TREM2 increases the risk of AD by 2 to 4.5 -fold, which makes this rare variant second only to ApoE- $\varepsilon 4$ in the strength of association to sporadic $\operatorname{AD}[18,20]$. The $\mathrm{R} 47 \mathrm{H}$ mutation of TREM2 alters the structure of the ligand-binding region and significantly reduces binding of phosphatidylserine (PtdSer), phosphatidylethanolamine, and sphingomyelin in biochemical assays $[21,22]$. In cells, reduced intracellular signalling of the $\mathrm{R} 47 \mathrm{H}$ mutation was confirmed in response to PtdSer, which is exposed on the surface of apoptotic cells as an "eat-me" signal for professional phagocytes $[13,23]$. R47H knock-in mice, crossed with the APPPS1-21 model to simulate AD pathology, suggest that the mutation phenocopies TREM2 knockout or haploinsufficiency models. Namely, there are fewer amyloid plaque-associated microglia, plaques are more diffuse, and microglia exhibit subtle defects in cytokine responses, survival, proliferation, and migration [24]. However, unlike human TREM2, R47H mutation of the mouse gene impairs TREM2 splicing and reduces mRNA and protein expression [25]. This makes the specific effect of the mutation impossible to interpret in R47H knock-in mouse models. Mouse models expressing human TREM2 should not manifest the same defect. Indeed, humanised $\mathrm{R} 47 \mathrm{H}$ TREM2-expressing mice crossed with the 5xFAD model have already been studied and exhibited reduced microglia clustering around amyloid plaques relative to human WT TREM2-5xFAD mice, [26]. The biological mechanisms underlying this phenotype are unexplained. 
Given the questions over the validity of different $\mathrm{R} 47 \mathrm{H}$ TREM2 mouse models, it is important to explore the cell phenotypes of R47H TREM2 in an authentic human model. Human induced pluripotent stem cells (iPSC) differentiated to microglia-like cells offer the most relevant model to date. Limited study of the phenotypic effects of the $\mathrm{R} 47 \mathrm{H}$ mutation has been made in iPSC-derived human microglia-like cells, with conflicting findings regarding the impact of the mutation upon phagocytosis [27, 28]. We have performed a broader and more systematic examination of cell phenotypes using isogenic wildtype, biallelic $\mathrm{R} 47 \mathrm{H}$, and TREM2 KO human iPSC differentiated to iPSC-macrophages (pMac). pMac are a simple model of human microglia that follow a primitive, Myb-independent differentiation, analogous to microglia ontogeny, and display close transcriptional similarity to human foetal microglia [29-31]. We show that TREM2 $\mathrm{KO}$ has minimal impact on LPS-induced inflammation; however, deficits are observed in phagocytosis, morphology, migration, and survival. R47H TREM2 has no significant effect on phagocytosis, morphology, migration, or survival, yet reduced IFN $\gamma$ primed TLR4-mediated inflammation. However, bulk RNA-seq revealed high overlap of altered gene expression in the R47H TREM2 pMac with the TREM2 $\mathrm{KO}$ and suggested that one of the most highly dysregulated pathways was adhesion to extracellular matrix. We used a bioinformatics approach to identify candidate stimuli that were predicted to reverse a subset of transcriptional defects in the TREM2 KO pMac, and tested one of the hits-TGF 1 - to ascertain whether treatment of TREM2 $\mathrm{KO}$ and $\mathrm{R} 47 \mathrm{H}$ TREM2 pMac would rescue both expression of the vitronectin receptor and adhesion of the cells to vitronectin.

\section{Methods}

\section{Key materials}

Live Cell Imaging solution, Fluo4-AM, CellTracker Deep Red, pHrodo iFL Red STP Ester, NucBlue live cell nuclear stain, NucGreen dead cell nuclear stain, and LIVE/DEAD fixable aqua stain were obtained from Invitrogen. DAPI was from Sigma, and paraformaldehyde (4\% in PBS) was obtained from Alfa Aesar. Human annexin V protein was from BD Biosciences, human C5a protein from Peprotech, human TGF $\beta 1$ from Miltenyi Biotec, and recombinant human IFNY and recombinant truncated human vitronectin from Gibco. Cytochalasin D was from Cayman Chemicals, Bafilomycin A1 from Abcam, and Jasplakinolide from Santa Cruz. PSB0739, MRS2179, MRS2211, and cilengitide were all obtained from Tocris. ADP, BSA, and crystal violet were from Sigma.

\section{iPSC culture}

iPSC lines BIONi010-C (control, BioSample ID: SAME A3158050, ECACC ID: 66540023), BIONi010-C-7 (R47H TREM2, BioSample ID: SAMEA4454010, ECACC
ID: 66540369), and BIONi010-C-17 (TREM2 KO, BioSample ID: SAMEA104386270, ECACC ID: 66540632) were obtained from Bioneer and are available from the European Collection of Authenticated Cell Cultures (ECACC). The parent line BIONi010-C was reprogrammed by Bioneer with a non-integrating episomal vector, using normal adult human skin fibroblasts sourced from Lonza (\#CC-2511). For some supplementary data, pMac differentiated from SFC840-03-03 iPSC were used, a previously published line derived from dermal fibroblasts from a disease-free donor recruited through the Oxford Parkinson's Disease Centre [32]. iPSC were cultured in $\mathrm{mTeSR}^{\mathrm{m}} 1$ media (STEMCELL Technologies), on hESC-qualified Geltrex-coated plates (Gibco), passaging as clumps using $0.5 \mathrm{mM}$ EDTA in PBS. Large-scale SNP quality-controlled batches were frozen at p15-25 and used for experiments within a minimal number of passages post-thaw to ensure consistency. An Illumina Omniexpress 24 v1.2 SNP microarray analysis was performed to verify genomic integrity, as previously described in [30].

\section{Human iPSC differentiation to $\mathrm{pMac}$}

iPSC were differentiated to primitive, tissue-type macrophages as previously described [29]. In brief, $4 \times 10^{6}$ iPSC were seeded into an Aggrewell-800 plate well (STEMCELL Technologies) to form embryoid bodies, in $\mathrm{mTeSR}^{\mathrm{mx}} 1$ media (STEMCELL Technologies), and fed daily with medium plus growth factors: $50 \mathrm{ng} / \mathrm{mL}$ BMP4 (Peprotech), $50 \mathrm{ng} / \mathrm{mL}$ VEGF (Peprotech), and $20 \mathrm{ng} / \mathrm{mL}$ SCF (Miltenyi Biotec). In a modification to the previously published protocol, the embryoid bodies were cultured for 5-6 days in growth factors instead of 4 days, and after the first 2 days they were transferred into lowadherence 6-well plates. Embryoid bodies were then differentiated in T175 flasks (150 per flask), known as "differentiation factories". iPSC-macrophage precursors (pMacpre), emerging into the supernatant after approximately 2-3 weeks, were harvested weekly, were plated in their final assay format, and were differentiated to pMac for $6-10$ days at $37^{\circ} \mathrm{C} / 5 \% \mathrm{CO}_{2}$, in X-VIVO15 with 100 $\mathrm{ng} / \mathrm{mL}$ M-CSF, $2 \mathrm{mM}$ Glutamax, $100 \mathrm{U} / \mathrm{mL}$ penicillin, and $100 \mu \mathrm{g} / \mathrm{mL}$ streptomycin.

\section{DNA sequencing of R47H mutation}

DNA was extracted from a cell pellet of iPSC using the DNeasy Blood \& Tissue kit from QIAGEN. A PCR reaction in $25 \mu \mathrm{L}$ was performed using Phusion HF buffer, 0.5 units Phusion HF DNA polymerase, $200 \mu \mathrm{M}$ dNTPs, $500 \mathrm{nM}$ forward primer (AAACACATGCTGTGCCAT CC), $500 \mathrm{nM}$ reverse primer (CACAGACGCCCAAAAC ATGAG), and genomic DNA (50-100 ng). PCR reaction: $1 \times\left(98^{\circ} \mathrm{C}, 30 \mathrm{~s}\right), 30 \times\left(98^{\circ} \mathrm{C}, 5 \mathrm{~s} ; 60.7^{\circ} \mathrm{C}, 10 \mathrm{~s} ; 72^{\circ} \mathrm{C}, 15 \mathrm{~s}\right)$, $1 \times 72^{\circ} \mathrm{C}, 5 \mathrm{~min}$. PCR products were sent for sequencing 
(Eurofins) with the reverse primer: TGATGGCTGT GCTCCCATTC.

\section{Western blotting}

pMacpre were seeded in either 12 -well plates $\left(8 \times 10^{5}\right.$ pMac per well) or 6 -well plates $\left(1.5 \times 10^{6}\right.$ pMac per well $)$ and differentiated for a week in macrophage media. Stimulations with a TREM2-activating antibody (goat polyclonal antibody against human TREM2 AF1828 from R\&D Systems) used a concentration of $2.4 \mu \mathrm{g} / 1 \times$ $10^{6}$ cells $(3.84 \mu \mathrm{g} / \mathrm{mL})$ for $10 \mathrm{~min}$. Stimulations with dead $\mathrm{SH}-\mathrm{SY} 5 Y$ s used a ratio of 3:1 SH-SY5Ys to pMac, with an initial $1 \mathrm{~h}$ incubation at $4{ }^{\circ} \mathrm{C}$ to allow cells to settle, followed by incubation at $37^{\circ} \mathrm{C}$ for the time periods indicated. After washing with PBS, pMac were lysed directly in modified RIPA buffer $(50 \mathrm{mM}$ Tris- $\mathrm{HCl}(\mathrm{pH}$ 7.4), $1 \%$ Triton $\mathrm{X}-100,0.5 \%$ sodium deoxycholate, $0.1 \%$ sodium dodecyl sulphate, $150 \mathrm{mM}$ sodium chloride, 2 $\mathrm{mM}$ ethylenediaminetetraacetic acid, $50 \mathrm{mM}$ sodium fluoride) with protease and phosphatase inhibitor cocktails (Roche). Lysates were sonicated for $30 \mathrm{~s}$ at medium power and centrifuged at $14000 \times g$ for $3 \mathrm{~min}$ to a pelletinsoluble material. Triton X-100-soluble proteins were boiled with $1 \times$ LDS sample buffer with reducing agent (Thermo Fisher), and samples were resolved by denaturing SDS-PAGE with 8-16\% Tris-glycine gels (Thermo Fisher). Subsequently, the separated proteins were transferred to low-fluorescence $0.2 \mu \mathrm{M}$-pore PVDF membrane (Thermo Fisher) using a Pierce Power Blotter semi-dry transfer apparatus (Thermo Fisher). Membranes were blocked for $0.5-2 \mathrm{~h}$ with iBind FD solution (Thermo Fisher) and incubated with primary antibodies in iBind solution overnight at $4{ }^{\circ} \mathrm{C}$. Primary antibodies for TREM2, phospho-SYK (Y525/Y526), total SYK, and GAPDH were purchased from commercial sources and are listed in Table 1 . Membranes were washed $3 \times 10$ min with Tris-buffered saline and $0.05 \%$ Tween-20 (TBS-T) and probed for $1 \mathrm{~h}$ at room temperature (RT) with secondary antibodies in iBind FD solution. Membranes were washed 4-6 $\times 10 \mathrm{~min}$ with TBS-T and developed with an Odyssey imaging system $\left(\mathrm{LI}-\mathrm{COR}^{\circ}\right)$. Optical densities of immunoreactivity were quantified using ImageStudio ${ }^{\text {тм }}$ Lite 5.2 software and normalised to the GAPDH control.

\section{Flow cytometry for surface proteins}

pMac were lifted from 6-well plates by incubation with StemPro Accutase (Gibco) for $10 \mathrm{~min}$ at $37^{\circ} \mathrm{C}$. The cells were washed with PBS and blocked in FACS buffer (PBS, 1\% FCS, $10 \mu \mathrm{g} / \mathrm{mL}$ human IgG) for $10 \mathrm{~min}$ at RT. $2 \times 10^{5}$ cells per sample were stained with directly conjugated primary antibodies against CD11b, CD14, CD45, $\alpha \mathrm{V} \beta 3$, or $\alpha \mathrm{V} \beta 5$, for $30 \mathrm{~min}$ on ice. A viability stain was included with the $\alpha \mathrm{V} \beta 3$ and $\alpha \mathrm{V} \beta 5$ antibodies (LIVE/
DEAD fixable aqua, Invitrogen). Cells were then washed 2-3 times with FACS buffer and fixed with $4 \%$ paraformaldehyde in PBS (Alfa Aesar) for $10 \mathrm{~min}$ at RT. Cells were spun down and re-suspended in PBS. CD11b, CD14, and CD45 staining was analysed with a FACS Calibur flow cytometer (BD Biosciences), whereas $\alpha \mathrm{V} \beta 3$ and $\alpha \mathrm{V} \beta 5$ were analysed with an LSRFortessa X20 flow cytometer (BD Biosciences). Fluorophore-conjugated isotype controls from the same manufacturers were used. The antibodies are listed in Table 1.

\section{Cell surface protein purification}

pMacpre were seeded at $2 \times 10^{6}$ cells/well in 6-well plates and differentiated for a week. Cell surface proteins were extracted using a Pierce Cell Surface Protein Isolation kit (Thermo Fisher). In brief, the plates of pMac were placed on ice and washed twice with cold PBS with $\mathrm{Ca}^{2+}$ and $\mathrm{Mg}^{2+}$. Cell surface proteins were biotinylated with $0.5 \mathrm{mg} /$ well of sulfo-NHS-SS-biotin for $30 \mathrm{~min}$ on ice. Free biotin was quenched with Quenching Buffer (Thermo Fisher); the cells were gently scraped into tubes, spun down, and washed with Tris-buffered saline. The cell pellets were lysed in RIPA buffer (50 mM Tris$\mathrm{HCl}$ (pH 7.4), 1\% Triton X-100, 0.5\% sodium deoxycholate, $0.1 \%$ sodium dodecyl sulphate, $150 \mathrm{mM}$ sodium chloride, $2 \mathrm{mM}$ EDTA, $50 \mathrm{mM}$ sodium fluoride) and briefly sonicated, and protein content was measured by Bradford protein assay (Bio-Rad). Total protein concentrations between samples were normalised, and an aliquot of normalised whole-cell lysate was saved for Western blotting. The remaining homogenates were incubated with twice the volume of Neutravidin beads (Thermo Fisher) overnight at $4{ }^{\circ} \mathrm{C}$ with rotation. Beads were washed three times by centrifugation and resuspension in Wash Buffer (Thermo Fisher). Cell surface proteins were eluted from the beads by boiling for 15 min with $1 \times$ "LDS Sample buffer" (Thermo Fisher) with $50 \mathrm{mM}$ DTT. Cell surface proteins and whole-cell lysates (containing proteins soluble in $1 \%$ Triton X-100) were analysed by Western blotting, including a negative control of non-biotinylated cells.

\section{Immunocytochemistry}

pMacpre were seeded at $4 \times 10^{4}$ cell/well in optically clear bottom CellCarrier 96-well plates (Perkin Elmer) and differentiated in macrophage media for a week. For cell surface staining of live pMac: cells were washed with cold PBS and incubated on ice for 20 min with primary antibody in a live-cell blocking buffer (PBS with 5\% BSA and $10 \mu \mathrm{g} / \mathrm{mL}$ human IgG). Cells were washed three times for 5 min with cold PBS, on ice, and incubated with secondary antibody in live-cell blocking buffer on ice for $15 \mathrm{~min}$. After three washes with cold PBS, cells were fixed with $2 \%$ paraformaldehyde in PBS for $20 \mathrm{~min}$ 
Table 1 Antibodies

\begin{tabular}{|c|c|c|c|c|c|c|}
\hline Target & Species raised in & Antibody conjugate & Identifier & Supplier & Conc. & Use \\
\hline TREM2 & Goat & - & AF1828 & R\&D Systems & $3.84 \mu \mathrm{g} / \mathrm{mL} / 1: 30$ & Stimulus/ICC \\
\hline TREM2 & Rabbit & - & EPR20243 & Abcam & $1: 500$ & WB \\
\hline SYK pY525/ pY526 & Rabbit & - & MA5-14918 & Thermo Fisher & $1: 200$ & WB \\
\hline Total SYK & Mouse & - & 4D10 & CST & $1: 500$ & WB \\
\hline Fibronectin & Rabbit & - & 15613-1-AP & Proteintech & $1: 500$ & WB \\
\hline GAPDH & Rabbit & - & G9545 & Sigma & $1: 2000$ & WB \\
\hline Tubulin & Mouse & - & T5168 & Sigma & 1:1000 & WB \\
\hline Rabbit lgG & Goat & IRDye ${ }^{\circledast} 800 \mathrm{CW}$ & $926-32211$ & LI-COR & 1:3000-1:5000 & WB \\
\hline Mouse lgG & Donkey & IRDye ${ }^{\circledast} 680 \mathrm{RD}$ & $926-68072$ & LI-COR & 1:3000-1:5000 & WB \\
\hline Calnexin & Rabbit & - & ab22595 & Abcam & $1: 1500$ & ICC \\
\hline TGN-46 & Rabbit & - & ab50595 & Abcam & $1: 100$ & ICC \\
\hline LAMP1 & Rabbit & - & 9091 & CST & $1: 200$ & ICC \\
\hline RAB9 & Rabbit & - & 5118 & CST & $1: 100$ & ICC \\
\hline TUJ1 & Mouse & - & 801201 & Biolegend & $1: 500$ & ICC \\
\hline Goat lgG & Donkey & Alexa Fluor 488 & A11055 & Thermo Fisher & $1: 1000$ & ICC \\
\hline Rabbit lgG & Donkey & Alexa Fluor 568 & A10042 & Thermo Fisher & $1: 500$ & ICC \\
\hline Rabbit lgG & Donkey & Alexa Fluor 647 & A31573 & Thermo Fisher & $1: 500$ & ICC \\
\hline Mouse lgG & Donkey & Alexa Fluor 647 & A31571 & Thermo Fisher & $1: 500$ & ICC \\
\hline IL-6 & Rat & - & 14-7069-81 & Thermo Fisher & $4 \mu \mathrm{g} / \mathrm{ml}$ & ELISA - capture \\
\hline IL-6 & Rat & Biotinylated & 13-7068-81 & Thermo Fisher & $2 \mu \mathrm{g} / \mathrm{ml}$ & ELISA - detection \\
\hline sTREM2 & Rabbit & - & ab209814 & Abcam & $8 \mu \mathrm{g} / \mathrm{ml}$ & ELISA - capture \\
\hline sTREM2 & Goat & Biotinylated & BAF1828 & R\&D Systems & $1.5 \mu \mathrm{g} / \mathrm{ml}$ & ELISA - detection \\
\hline CD11B & Mouse (IgG1k) & APC & 301309 & Biolegend & $1: 25$ & FC \\
\hline CD14 & Mouse (IgG1) & PE & 21620144 & Immuno-tools & $1: 25$ & FC \\
\hline CD45 & Mouse (IgG1) & APC & 21335014 & Immuno-tools & $1: 25$ & FC \\
\hline aVß3 & Mouse (lgG1k) & APC & 304415 & Biolegend & $1: 50$ & FC \\
\hline aVß5 & Mouse (lgG1) & PE & FAB2528P & R\&D Systems & $1: 50$ & FC \\
\hline Control & Mouse (lgG1k) & APC & 400119 & Biolegend & $1: 50$ & FC \\
\hline Control & Mouse (lgG1) & PE & 21335014 & Immuno-tools & $1: 25$ & FC \\
\hline Control & Mouse (lgG1) & APC & 21275516 & Immuno-tools & $1: 25$ & FC \\
\hline Control & Mouse (lgG1) & PE & IC002P & R\&D Systems & $1: 50$ & FC \\
\hline
\end{tabular}

List of antibodies used in this study. WB Western blot, ICC immunocytochemistry, FC flow cytometry

at RT, then washed with PBS. The cells were permeabilized and counterstained with DAPI as below. For total staining of permeabilized cells: cells were fixed in 2\% paraformaldehyde in PBS (Alfa Aesar) for 20 min at RT, washed with PBS, permeabilized with $0.1 \%$ Triton $\mathrm{X}-100$ in PBS for $10 \mathrm{~min}$ at RT, and blocked overnight at $4{ }^{\circ} \mathrm{C}$ in blocking buffer (PBS, $0.05 \%$ Triton-X100, $10 \%$ normal donkey serum, $5 \% \mathrm{BSA}, 0.01 \% \mathrm{NaN}_{3}$ ). Cells were incubated with primary antibodies for $1 \mathrm{~h}$ at RT, washed $3 \times 15$ min with $0.3 \%$ Triton X-100 in PBS, and incubated with secondary antibodies for $1 \mathrm{~h}$ at RT. Primary antibody for TREM2 (AF1828, 1:30, R\&D Systems) was used in combination with either of the following primary antibodies for subcellular markers: TGN-46, calnexin,
RAB11, LAMP1, TUJ1, and RAB9. Secondary antibodies were anti-goat IgG-Alexa Fluor 488 for TREM2, antirabbit IgG-Alexa Fluor 568 for TGN-46, calnexin, RAB11 and LAMP1, anti-mouse IgG-Alexa Fluor 647 for TUJ1, and anti-rabbit IgG-Alexa Fluor 647 for RAB9. The antibodies used are listed in Table 1. A DAPI nuclear counterstain (1:2000, Sigma) was incubated for 15 $\mathrm{min}$ at RT, and the cells washed $4 \times 15 \mathrm{~min}$. Images were acquired with an Opera Phenix High Content Screen System (Perkin Elmer) with a $63 x$ water objective, Zstacks of 9 fields per well, and 3 wells per condition. Columbus 2.7 software (Perkin Elmer) was used to generate a co-localization index for co-localization of TREM2 with intracellular markers. The analysis pipeline 
defined intracellular regions as "ER", or "TGN", or "lysosome" based upon the intensity and pattern of subcellular marker staining: "ER" is a tubular pattern of calnexin, "TGN" is a single large focal structure of TGN46 per cell, and "lysosome" is a punctate pattern of LAMP1. Calculated within these defined regions, the colocalization index used is (intensity of TREM2)/ (intensity of subcellular marker).

\section{ELISAs}

For TGF $\beta 1$, pMacpre were seeded at $1.2 \times 10^{6}$ cell/well in 6-well plates in full macrophage media, and the media were replaced after 7 days with $1 \mathrm{~mL}$ full media $\pm 2 \mu \mathrm{M}$ OXSI-2 for a further $24 \mathrm{~h}$ incubation at $37^{\circ} \mathrm{C} / 5 \% \mathrm{CO}_{2}$. Supernatants were spun down and stored in aliquots at $-80^{\circ} \mathrm{C}$. TGF $\beta 1$ was quantified using a Human/Mouse TGF beta-1 Uncoated ELISA Kit (Invitrogen), in accordance with the manufacturer's protocol.

For sTREM2/IL-6/TNF, pMacpre were seeded at $4 \times$ $10^{4}$ cells/well in optically clear bottom CellCarrier 96well plates (PE) and differentiated in macrophage media for a week. In triplicate wells, cells were stimulated for $24 \mathrm{~h} \pm 100 \mathrm{ng} / \mathrm{mL}$ IFN $\gamma$. All wells were given a full media change to $70 \mu \mathrm{L}$ macrophage media $\pm E$. coli lipopolysaccharide (LPS) and incubated for $4 \mathrm{~h}$ at $37^{\circ} \mathrm{C} / 5 \% \mathrm{CO}_{2}$. Supernatants were spun down and stored in aliquots at $-80^{\circ} \mathrm{C}$. For cell counting, cells were stained with NucBlue Live ReadyProbes Reagent (Invitrogen), and nuclei counting was performed using an EVOS FL Auto automated microscope (Thermo Fisher) at $4 \mathrm{x}$ objective, 4 fields per well, and CellProfiler 2.2 software [33]. Supernatant TNF was quantified using a TNFa Human Uncoated ELISA Kit (Invitrogen), in accordance with the manufacturer's protocol. An in-house ELISA was used to measure IL-6 and sTREM2, from the same supernatants measured for TNF, except with triplicate wells pooled. For in-house IL-6/TREM2 ELISA procedure, Greiner high-bind 96-well plates (Sigma) were coated with appropriate capture antibody (detailed in Table 1 for each ELISA) overnight at $4{ }^{\circ} \mathrm{C}$. Plates were washed with PBS $+0.05 \%$ Tween 20 and incubated with blocking buffer (PBS, $0.05 \%$ Tween20, and 1\% BSA) to block nonspecific binding sites. A standard curve was generated using human recombinant IL-6 or TREM2 (Sino Biologicals). Standard and diluted supernatants were incubated for $2 \mathrm{~h}$ at RT. After washing, plates were incubated with the appropriate biotinylated detection antibody (Table 1) for $1 \mathrm{~h}$ at RT. Plates were washed $3 \mathrm{x}$ in PBS-T, then incubated with HRP-conjugated streptavidin (Thermo Fisher Scientific) for $1 \mathrm{~h}$ at RT. Plates were washed and incubated with 1-Step Ultra TMB ELISA substrate solution (Thermo Fisher Scientific). The reaction was stopped with $2 \mathrm{~N} \mathrm{H}_{2} \mathrm{SO}_{4}$, and the chemiluminescent signal was measured on a plate reader at $450 \mathrm{~nm}$. Data from each well was normalised to the average cell count for that condition, and further normalised to the average $\mathrm{pg} / \mathrm{mL} /$ cell for the whole ELISA plate. The in-house ELISA antibodies are listed in Table 1.

\section{Calcium assay}

pMacpre were seeded at $1 \times 10^{4}$ cells/well in optically clear bottom CellCarrier 384-well plates (Perkin Elmer) and differentiated in macrophage medium for 7 days. The stimuli used were $0.5 \mathrm{mM}$ ATP (Sigma) and $10 \mu \mathrm{g} /$ mL TREM2 antibody (R\&D Systems). A 384-well plate containing stimuli was prepared for transfer onto the pMac. pMac were loaded with $25 \mu \mathrm{L}$ of $4 \mu \mathrm{M}$ calciumsensitive dye Fluo4-AM (Thermo Fisher Scientific) in the presence of $0.5 \%$ pluronic acid (Life technologies) diluted in HBTS buffer (HEPES Buffered Tyrode's Solution: $\mathrm{NaCl} 135 \mathrm{mM}, \mathrm{KCl} 5 \mathrm{mM}, \mathrm{MgCl}_{2} 1.2 \mathrm{mM} . \mathrm{CaCl}_{2}$ $2.5 \mathrm{mM}$, HEPES $10 \mathrm{mM}$, glucose $11 \mathrm{mM}, \mathrm{pH} 7.2$ ) for $1 \mathrm{~h}$ at RT. pMac were washed with HBTS before the plates of pMac, and stimuli were loaded onto the FLIPR Tetra (Molecular Devices), a high-throughput cell-based screening system with a robotic pipettor. Each condition was run in quadruplicate. Relative fluorescent units (RFU) of the assay plate were read with the excitation/ emission pairs 470-495 nm LEDs and 515-575 nm emission filters. Settings were adjusted in order to have values of $\sim 1000$ RFUs at baseline. Basal fluorescence was measured for $1 \mathrm{~min}$, and following injection of stimuli, the response was recorded for $5 \mathrm{~min}$ at reading intervals of $5 \mathrm{~s}$ using the ScreenWorks software. Data was exported as maximum-minimum signal and RFU normalised to baseline values set to $100 \%$.

\section{Generation of dead SH-SY5Ys}

SH-SY5Ys (ATCC) were cultured in T75 flasks with DMEM/F12 media (Gibco) with 10\% FBS (Sigma) and penicillin/streptomycin (Invitrogen), and maintained at $37^{\circ} \mathrm{C} / 5 \% \mathrm{CO}_{2}$. Cells were harvested with TrypLE Express (Gibco), washed with Hank's Balanced Salt Solution (HBSS, Gibco), centrifuged at $400 \times g$ for $5 \mathrm{~min}$, and re-suspended in $2 \mathrm{~mL}$ Live Cell Imaging Solution (LCIS, Invitrogen). Paraformaldehyde (Alfa Aesar) was added to a final concentration of $2 \%$, and the cells were fixed for $10 \mathrm{~min}$ at RT. The cells were washed again with HBSS and centrifuged at $1200 \times g$ for $7 \mathrm{~min}$.

\section{Generation of rat cortical synaptosomes}

Two wildtype female ex-breeder Sprague-Dawley rats (Charles River) were sacrificed using a $\mathrm{CO}_{2}$ procedure, in accordance with the approved humane killing protocols detailed in Schedule 1 of the Animals in Scientific Procedures Act, 1986, and the brain cortices dissected. Synaptosomes were purified from the fresh cortices using a previously described method of Percoll gradient 
fractionation, with four Percoll gradients per rat [34]. An aliquot of the purified synaptosomes was dissolved in $1 \%$ NP-40 and the protein concentration determined by Bradford assay. Accordingly, the synaptosomes were diluted to $1 \mathrm{mg} / \mathrm{mL}$ of their total protein content with HEPES-buffered media ( $\mathrm{pH} 7.4,140 \mathrm{mM} \mathrm{NaCl}$ (VWR), $5 \mathrm{mM} \mathrm{KCl}$ (VWR), $5 \mathrm{mM} \mathrm{NaHCO}_{3}$ (Sigma), $1.2 \mathrm{mM}$ $\mathrm{NaH}_{2} \mathrm{PO}_{4}$ (Sigma), $1 \mathrm{mM} \mathrm{MgCl} \cdot 6 \mathrm{H}_{2} \mathrm{O}$ (Sigma), $10 \mathrm{mM}$ glucose (VWR), $1 \mathrm{mg} / \mathrm{ml}$ BSA (Sigma), $10 \mathrm{mM}$ HEPES (Sigma)) with $5 \%(\mathrm{v} / \mathrm{v})$ DMSO and frozen in single-use aliquots at $-80^{\circ} \mathrm{C}$. Thawed synaptosomes were characterised by negative staining transmission electron microscopy, performed by the Sir William Dunn School of Pathology Electron Microscopy Facility. Upon thawing, synaptosomes were centrifuged at $3000 \times g$ for $10 \mathrm{~min}$ at $4{ }^{\circ} \mathrm{C}$ and washed once with Live Cell Imaging Solution (Invitrogen), to remove residual BSA before pHrodolabelling.

\section{Annexin V-FITC staining for phosphatidylserine}

Phosphatidylserine exposure of phagocytic cargo was visualised using an annexin V-FITC Apoptosis Detection Kit (Abcam). One day prior to staining, SH-SY5Ys were seeded to $50 \%$ confluence in a 24 -well plate. Synaptosomes were thawed, washed, and re-suspended in annexin binding buffer, and approximately $0.3 \mu \mathrm{g}$ per well was added to empty wells of the plate, allowing an hour to settle at $37{ }^{\circ} \mathrm{C} / 5 \% \mathrm{CO}_{2}$. SH-SY5Ys were washed with HBSS and some wells fixed with $2 \%$ paraformaldehyde for $10 \mathrm{~min}$, before another wash, replacing with annexin binding buffer containing NucBlue. Both SHSY5Ys and synaptosomes, except for unstained controls, were stained with 1:70 annexin V-FITC and 1:70 propidium iodide for $5 \mathrm{~min}$. Propidium iodide stains nuclei of permeable cells, controlling for annexin $\mathrm{V}$ staining of the plasma membrane inner leaflet. The plate was imaged at $37^{\circ} \mathrm{C} / 5 \% \mathrm{CO}_{2}$ using an EVOS FL Auto automated microscope (Thermo Fisher) with on-stage incubator at 40x objective with phase and using the DAPI, GFP, and Texas Red light cubes.

\section{Phagocytosis assays}

pMacpre were seeded at $2 \times 10^{4}$ cells/well in optically clear bottom CellCarrier 96-well plates (Perkin Elmer) and differentiated in macrophage media for a week. Cells were stained for $45 \mathrm{~min}$ at $37^{\circ} \mathrm{C} / 5 \% \mathrm{CO}_{2}$ with $1 \mu \mathrm{M}$ CellTracker Deep Red (Invitrogen) and $1 \mathrm{drop} / \mathrm{mL}$ NucBlue Live ReadyProbes Reagent (Invitrogen). Cells were washed with PBS, and then incubated for $1 \mathrm{~h}$ at $37^{\circ} \mathrm{C} /$ $5 \% \mathrm{CO}_{2}$ with $100 \mu \mathrm{L}$ of Live Cell Imaging Solution (LCIS, Invitrogen) \pm phagocytosis inhibitors, before addition of phagocytic cargo. Phagocytosis inhibitors used for validation were $10 \mu \mathrm{M}$ cytochalasin D (Cayman), $1 \mu \mathrm{M}$ bafilomycin A1 (Abcam), $1 \mu \mathrm{M}$ jasplakinolide (Santa Cruz), and $2 \mu \mathrm{g}$ unlabelled human recombinant annexin V (BD Biosciences). Annexin V was added to well immediately prior to addition of phagocytic cargo. The phagocytic cargo- synaptosomes or dead SH-SY5Ys- were stained with pHrodo iFL Red STP Ester (Invitrogen), using $20 \mu \mathrm{g}$ of dye per $1 \mathrm{mg}$ synaptosomes, or $12.5 \mu \mathrm{g}$ of dye per $1 \times 10^{6} \mathrm{SH}-\mathrm{SY} 5 Y \mathrm{~s}$, aiming for a final concentration of $40 \mu \mathrm{g} / \mathrm{mL}$. pHrodolabelling was performed for $30 \mathrm{~min}$ at $\mathrm{RT}$, protected from the light, in a low protein-binding tube. Cargo was washed twice with HBSS, (centrifugation: $3000 \times g$ synaptosomes, $1200 \times g$ dead SH-SY5Ys) and re-suspended in LCIS to a concentration of $0.6 \mu \mathrm{g} / \mu \mathrm{L}$ synaptosomes or $8 \times 10^{5}$ cells $/ \mathrm{mL} \mathrm{SH-SY5Ys,} \mathrm{and} 50 \mu \mathrm{L} /$ well added to the pMac. Phagocytosis was performed at $37^{\circ} \mathrm{C} / 5 \% \mathrm{CO}_{2}$ for $0.5-5 \mathrm{~h}$, in triplicate wells. Cells were fixed with $2 \%$ paraformaldehyde in PBS (Alfa Aesar) for $15 \mathrm{~min}$ at RT and washed with PBS before imaging. For staining TREM2, TUJ1, and RAB9a, immunocytochemistry was performed on permeabilized cells as described above. Images were taken with an INCell Analyzer 6000 highcontent imaging system (GE Healthcare Life Sciences) with a 40x objective, 9 fields/well on a single plane. Images were quantified with Columbus 2.7 software (Perkin Elmer). The parameters measured for each field were average number of spots/cell, the sum of the spot areas, and the \% spot-positive cells. Data was averaged for the technical replicates and normalised to the overall plate average, to adjust for differences between plates.

\section{Transwell assays}

pMacpre were seeded at $1.2 \times 10^{6}$ cells/well in 6-well plates and differentiated in macrophage media for a week. Cells were dissociated with StemPro Accutase (Gibco) for $10 \mathrm{~min}$ at $37^{\circ} \mathrm{C}$ and washed with PBS. pMac were re-suspended in cold macrophage media, and $100 \mu \mathrm{L}$ with $5.5 \times 10^{4}$ cells was pipetted onto transwells (PET with $5 \mu \mathrm{m}$ pores, Sarstedt) suspended over wells of an empty 24 -well plate. In total, $600 \mu \mathrm{L}$ of macrophage media \pm inhibitors was added beneath the transwells and incubated $30 \mathrm{~min}$ at $\mathrm{RT}$, before the chemotactic stimulus was added: $30 \mu \mathrm{M}$ ADP (Sigma) or $3 \mathrm{nM}$ human recombinant C5a (Peprotech). The 24-well plates were incubated for $6 \mathrm{~h}$ to allow cell migration. After cell migration, the transwells were gently rinsed with PBS, transferred to a fresh 24-well plate, and fixed with $4 \%$ paraformaldehyde (Alfa Aesar) for $20 \mathrm{~min}$ at RT. Cells were stained with NucBlue (Invitrogen) nuclear stain and imaged with an EVOS FL Auto automated microscope (Thermo Fisher), $4 \times$ with DAPI light cube, set up to scan each transwell in full and generate a knitted single image. The transwells were swabbed with a cotton wool bud to remove cells on the top surface, leaving behind only migrated cells, transferred into a fresh plate 
with fresh PBS, and imaged again with the same settings. Nuclei counting was performed with CellProfiler2.2 software [33], and for each transwell, the \% migration was calculated: (no. cells in second scan) $\div$ (no. cells in first scan $) \times 100$. Treatments were performed in duplicate and duplicate wells were averaged, then normalised to the average \% migration for the entire plate, to control for age-dependent differences in cell speed.

\section{Survival assay}

pMacpre were seeded at $4 \times 10^{4}$ cells/well in three optically clear bottom black 96-well plates (Costar) and differentiated in macrophage media. After 7 days, a full media change was performed to $100 \mu \mathrm{L}$ macrophage media $\pm \mathrm{M}$ CSF, triplicate wells for each condition on each plate. Plates were incubated at $37^{\circ} \mathrm{C} / 5 \% \mathrm{CO}_{2}$ for 3,7 , or 10 days, and the 10-day plate received a $50 \%$ media change at 7 days. At the end of each incubation, cells were stained 20 min $\left(37^{\circ} \mathrm{C} / 5 \% \mathrm{CO}_{2}\right)$ with the ReadyProbes Cell Viability Imaging Kit (Invitrogen). Nuclei counting was performed using an EVOS FL Auto automated microscope (Thermo Fisher), 4x objective with DAPI and GFP light cubes, 4 fields/well, and CellProfiler 2.2 software [33]. Data was presented as (mean number of dead cells/mean number of total cells) $\times 100$ for each condition.

\section{RNA-seq sample and library preparation}

pMacpre were seeded at $1.5 \times 10^{6}$ cells/well in 6-well plates at 7,8 , and 9 weeks after setting up differentiation factories, and they were differentiated in macrophage media for 7 days. Cells were washed once with PBS, aspirated thoroughly, and lysed by addition of $350 \mu \mathrm{L}$ Buffer RLT (QIAGEN) with 1\% (v/v) 2-mercaptoethanol. Plates were stored at $-80^{\circ} \mathrm{C}$ until all samples were collected, and then lysates were passed through QIAshredder columns (QIAGEN) and the total RNA extracted using a QIAGEN RNeasy Mini kit, according to the manufacturer's protocol using on-column DNase treatment (QIAGEN). RNA samples were eluted in $30 \mu \mathrm{L}$ of RNase-free water. The quantity and quality of RNA was measured by Nanodrop and RNA Tapestation (Agilent), with measured RNA integrity (RIN) values $\geq 8.4$. Poly-A library preparation and sequencing (HiSeq 4000, $75 \mathrm{bp}$ paired-end reads), and basic data processing, was conducted at the Oxford Genomics Centre, Wellcome Centre for Human Genetics.

\section{Analysis of RNA-seq data}

Quantified transcript abundance counts were obtained with the tool Salmon (v0.12.0)(PMID: 28263959) using mapping-based mode with default parameters, automatic library type-inference, and the additional command line arguments "validatemappings", "seqBias", "posBias", and "gcBias", in order to enable selective alignment of the sequencing reads, and account for sequence-specific biases, fragment-level GC biases, and $5^{\prime}$ or $3^{\prime}$ positional biases in the data. The paired-end sequencing reads for each sample were mapped to the human reference transcriptome (GRCh38; Ensembl release 95), which combined cDNA and ncRNA. The transcript abundances were imported and summarised to gene-level counts using the R library "tximport" (PMID: 26925227).

Only the protein-coding genes were used, and data were filtered to include genes $(n=15,341)$ with $>10$ counts across all samples. Differential gene expression between the TREM2 KO vs WT and TREM2 R47H vs WT was performed on genes expressed across all samples with the R library "DESeq2" (PMID: 25516281) using the Wald test, and LFC shrinkage was performed using the "ashr" method (PMID: 27756721). We considered a gene to be differentially expressed at FDR $<0.05$. Principal component analysis was performed using the "prcomp" function in $\mathrm{R}$, on variance-stabilising transformed data for all genes. PC1 was added as a covariate to the design model, to remove the influence of the covariate "differentiation age" on the differential expression. Gene ontology enrichment analysis was performed with the R library ClusterProfiler (PMID: 22455463) and adjusted $p$ values for multiple testing following a Benjamini-Hochberg correction, and terms were filtered out if they were associated with fewer than 10 differentially expressed genes. All plotting was performed with multiple libraries in $\mathrm{R}$.

\section{Gene functional network and clustering method}

A combined protein-protein interaction (PPI) network was created based on diverse resources: BioGRID 3.4 (accessed on September 2017) [35], HitPredict (accessed on September 2017) [36], IntAct (accessed on September 2017) [37], STRING (accessed on September 2017, restricted to Homo sapiens and experimental scores higher than zero) [38], CORUM (accessed on September 2017) [39], and Reactome (accessed on September 2017) [40]. The combined network consisted of a total of 20,591 genes and 1,973,967 interactions. A gene functional network was built for the differentially expressed genes between TREM2 KO and WT samples, by using the top $500 \mathrm{~K}$ PPI interactions. To identify modules of highly interconnected genes in the network, we employed "cluster_louvain" function in "igraph" R library [41], where proteins in clusters with fewer than 30 members were grouped into a cluster with the label "0".

\section{Randomisation for PPI network analysis}

The randomisation approach takes into account both coding sequence length and the number of PPIs of the corresponding proteins. For every input gene, a random gene with similar coding sequence length and similar 
connectivity of its corresponding protein was selected, by applying a binning approach (PMID: 25319962). A total of 10,000 random gene sets, of the same size as the number of differentially expressed genes, were tested for their connectivity within the combined PPI network, and the number of connections were compared to the one obtained using the list of differentially expressed genes for TREM2 KO vs WT samples. The PPI analysis was performed on the basis of pairs of genes (using ensembl gene IDs annotated in combined PPI network), which means that an interaction between two genes is reported and counted if any of the possible gene products show an interaction.

\section{External dataset comparison}

Processed FPKM counts for RNA-seq data from Abud et al. [42] were downloaded from GEO: GSE89189 and were filtered to include only protein-coding genes that were common with the RNA-seq data in this study. The study batch-effect of the combined log2-transformed FPKM gene expression levels was removed by using the "ComBat" function in the "sva" $\mathrm{R}$ library (PMID: 22257669) and hierarchical clustering of the Euclidean distances of the samples was performed using the "ward. D2" method, and the dendrogram visualised with the "dendextend" R library. A scatter plot was made using $\mathrm{R}$ library "ggplot2" of significant $(F D R<0.05)$ differentially expressed genes for TREM2 KO vs WT from the Claes et al. RNA-seq study [27], against the significant results for TREM2 KO vs WT from the current study.

\section{Ingenuity pathway analysis}

For each of the PPI modules of differentially expressed genes, we identified upstream regulators using Ingenuity Pathway Analysis software [43]. The algorithm takes into account the observed gene expression changes, and the manually curated Ingenuity Knowledge Base, to infer the "activated" or "inhibited" state of upstream regulators (including transcription factors, small molecules, microRNA, and other genes). The "Regulators Effect" algorithm takes into account each identified upstream regulator and links it through the Ingenuity Knowledge Base to functions, phenotypes, and disease. Briefly, it takes the best matching pair (regulator and downstream effect networks) and tests for overlapping sets with a Fisher exact test and then iteratively groups regulators to both increase consistency and reduce redundancy of the network.

\section{qRT-PCR}

pMacpre were seeded at $0.8 \times 10^{6}$ cells/well in 12-well plates, differentiated in macrophage media for 7 days, and stimulated $\pm 50 \mathrm{ng} / \mathrm{mL}$ TGF $\beta 1$ (Miltenyi Biotec) for $24 \mathrm{~h}$. Cells were washed once with PBS, aspirated thoroughly, and lysed by addition of $350 \mu \mathrm{L}$ Buffer RLT (QIAGEN) with $1 \%(\mathrm{v} / \mathrm{v}) 2$-mercaptoethanol. Plates were stored at $80^{\circ} \mathrm{C}$, and RNA extracted as detailed for the RNA-seq sample preparation above. Reverse transcription was performed using a High-Capacity RNA-to-cDNA kit (Applied Biosystems), with $400 \mathrm{ng}$ RNA input per reaction, following the manufacturer's protocol. qRT-PCR was performed using TaqMan probes and TaqMan Gene Expression Master-mix (Applied Biosystems) in a 384-well PCR plate, $2 \mu \mathrm{L}$ cDNA in a final volume of $6 \mu \mathrm{L}$ per well, on a QuantStudio 5 qRT-PCR machine (Applied Biosystems). Taqman probes were CHCHD2 (Hs00855326_g1), ITGAV (Hs00233808_m1), ITGB3 (Hs01001469_m1), ITGB5 (Hs00174435_m1), FN1 (Hs01549976_m1), LAMB2 (Hs00158642_m1), SDC4 (Hs01120908_m1), GPC4 (Hs00155059_m1), and TBP (Hs00427620_m1). Samples were run in triplicate wells. $\Delta \Delta \mathrm{Ct}$ values were calculated using the average $\mathrm{Ct}$ for each triplicate: $\Delta \mathrm{Ct}$ was generated by subtraction of the average $\mathrm{Ct}$ for reference gene $T B P$, and then the $\Delta \mathrm{Ct}$ was normalised to the average $\Delta \mathrm{Ct}$ for all WT unstimulated samples (by subtraction).

\section{Adhesion assay}

pMacpre were seeded at $1.2 \times 10^{6}$ cell/well in 6-well plates in full macrophage media, and the media replaced after 6 days with $1 \mathrm{~mL}$ full media $\pm 50 \mathrm{ng} / \mathrm{mL}$ TGF $\beta 1$ (Miltenyi Biotec) for a further $24 \mathrm{~h}$ incubation at $37^{\circ} \mathrm{C} /$ $5 \% \mathrm{CO}_{2}$. Wells of a clear 96-well flat-bottomed plate were coated with $0.5 \mu \mathrm{g} /$ well $\left(1.56 \mu \mathrm{g} / \mathrm{cm}^{2}\right)$ truncated vitronectin (Gibco) in PBS, by incubation at room temperature for $1 \mathrm{~h}$. The vitronectin was aspirated, and remaining non-specific binding sites were blocked with a solution of $10 \mathrm{mg} / \mathrm{mL}$ denatured bovine serum albumin (BSA) in PBS for $1 \mathrm{~h}$. Wells were washed once with PBS, and $50 \mu \mathrm{L}$ of Live Cell Imaging Solution (LCIS; Invitrogen) \pm cilengitide added ( $10 \mu \mathrm{M}$ final well concentration). pMac dissociated from the 6-well plates by StemPro Accutase (Gibco) were pelleted and re-suspended in LCIS, and $50 \mu \mathrm{L}$ added to the vitronectin-coated wells at a density of $5 \times 10^{4}$ cells/well. Cells were also added to no-vitronectin BSA-blocked wells as a control for nonspecific binding. Adhesion was performed for $3 \mathrm{~h}$ at $37^{\circ} \mathrm{C} / 5 \% \mathrm{CO}_{2}$, and then the plate was washed once with PBS and cells fixed for 10 min in $4 \%$ paraformaldehyde at RT. Following two PBS washes, the cells were stained with crystal violet solution $(0.1 \%(\mathrm{w} / \mathrm{v})$ in $50 \mathrm{mM}$ MES, $150 \mathrm{mM} \mathrm{NaCl}, \mathrm{pH}$ 6) for $1 \mathrm{~h}$ at RT. Wells were washed 3 times with $\mathrm{dd}_{2} \mathrm{O}$, and the cells and dye were solubilised with $50 \mu \mathrm{L}$ of $10 \%(\mathrm{v} / \mathrm{v})$ acetic acid. Absorbance was measured at $570 \mathrm{~nm}$ on a microplate spectrometer, normalised to the non-specific binding controls.

\section{Statistical analysis}

Statistical analysis of the data was performed in GraphPad Prism software (version 7 for Windows), GraphPad 
Software, La Jolla, CA, USA, www.graphpad.com. All "n" numbers represent independent biological replicates, i.e., separate harvests of the differentiation cultures, with experiments performed independently on different weeks. Means were obtained from three or more independent repeats, and paired $t$-tests and one-way or two-way ANOVAs performed where appropriate, with Bonferroni, Sidak, or Dunnett corrections for multiple comparison. $P$ values $<0.05$ were considered to be significant and are indicated as follows: $" p<0.05,{ }^{* * *} p<0.01$, ${ }^{* * * *} p<$

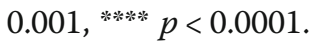

\section{Results}

\section{R47H TREM2 has reduced cell surface expression} compared with WT

Human microglia can be effectively modelled in vitro by the differentiation of human iPSC, via our previously published protocol for primitive, tissue-type macrophages, pMac $[29,31]$. pMac have a similar transcriptional signature to iPS-microglia co-cultured with neurons and express high levels of microglial genes [30]. We used three iPSC lines generated by Bioneer with the R47H TREM2 mutation inserted homozygously, and a TREM2 knockout, both on the same genetic background as the control WT iPSC line. We independently validated the R47H mutation by DNA sequencing and the TREM2 knockout by Western blotting (Additional file 1: Figs. S1, S3). After differentiating the iPSC lines to pMac, we confirmed that a similarly high efficiency of differentiation was achieved between the three lines, using surface markers CD11b, CD14, and CD45 (Additional file 1: Fig. S3). Interestingly, although $>80 \%$ of cells were positive for CD11b/CD14/CD45 in all three genotypes, we found that both the R47H TREM2 and TREM2 KO lines had significantly lower CD11b expression and higher CD14 expression than the WT, perhaps signifying changes to basal activation state.

In this study, we aimed to characterise the effect of the $\mathrm{R} 47 \mathrm{H}$ mutation on TREM2 protein expression, and on cell phenotypes, as illustrated in the diagram in Fig. 1a. TREM2 total protein levels in the R47H TREM2 line were unchanged relative to the WT line (Additional file 1: Fig. S3). TREM2 functions at the cell surface; therefore, proteins were purified by cell surface biotinylation and TREM2 detected by Western blotting, with comparison to the input cell homogenate (Fig. 1b). Surprisingly, the R47H TREM2 mutation showed significantly reduced cell surface levels of TREM2 by an average of $52 \%$ compared to the WT line in this assay (Fig. 1c). This difference in surface TREM2 was confirmed by immunocytochemistry of intact pMac (Additional file 1: Fig. S3), using an antibody that we confirmed is specific to TREM2 (unlike others, see Additional file 1: Fig. S4). Reduced surface TREM2 levels could be a consequence of either increased shedding from the membrane by regulated intra-membrane proteolysis [19, 44], TREM2 retention in the secretory pathway, or more TREM2 targeted to the lysosome for degradation. To distinguish these alternatives, we measured levels of TREM2 shedding by detecting the soluble TREM2 ectodomain (sTREM2) in conditioned media by ELISA and found that the R47H TREM2 pMac produced significantly higher levels of sTREM2 than WT in $4 \mathrm{~h}$ (Fig. 1d). This inverse relationship with cell surface TREM2 levels (Fig. 1c) supports the explanation that $\mathrm{R} 47 \mathrm{H}$ increases TREM2 shedding. We also investigated TREM2 intracellular localization: immunocytochemistry of permeabilized pMac was used to measure co-localization of TREM2 with markers for the endoplasmic reticulum (ER), trans-Golgi network (TGN), and lysosomes. High levels of TREM2 in the TGN, and weak localization to the ER and lysosomes was observed; however, TREM2 localization between the WT and R47H pMac was not significantly different, although there was a trend towards reduced R47H TREM2 in the TGN (Fig. 1e, f). Taken together, the data suggests that $\mathrm{R} 47 \mathrm{H}$ does not significantly alter TREM 2 protein trafficking or maturation, but elevates shedding in pMac.

Stimulation of TREM2-DAP12 activates the kinase SYK [5], which can be identified by Western blotting with an antibody specific for double phosphorylation at Y525 and Y526 [38]. Additionally, SYK activation leads to release of intracellular calcium stores via phospholipase $C$, which can be measured by a live-cell fluorescent assay for calcium flux. To investigate functionality of the TREM2-DAP12 complex, a specific TREM2-activating antibody (AF1828, R\&D Systems) was used to stimulate downstream signalling in pMac. The TREM2 antibody induced both SYK phosphorylation and calcium flux, which was absent in TREM2 KO pMac but unaffected by $\mathrm{R} 47 \mathrm{H}$ TREM2, demonstrating that the $\mathrm{R} 47 \mathrm{H}$ mutation does not alter TREM2 activity when a strong stimulus is applied (Fig. 1g-i, Additional file 1: Fig. S3).

\section{Several functional and morphological defects identified in TREM2 KO pMac are not exhibited by R47H TREM2 cells Phagocytosis of dead SH-SY5Ys and synaptosomes is impaired in TREM2 KO but not R47H pMac}

Loss of functional TREM2 has been previously reported to reduce microglial clearance of apoptotic neurons [6]. Phagocytosis of apoptotic neurons was modelled using two different phagocytic cargoes (for time-lapse videos, see Additional files 2 and 3): undifferentiated SH-SY5Ys that were freshly fixed with paraformaldehyde, and rat cortical synaptosomes, which are a synapse-enriched fraction of rat cortex (Additional file 1: Fig. S6). Fixing cells with paraformaldehyde has been previously reported to induce surface phosphatidylserine exposure, a 

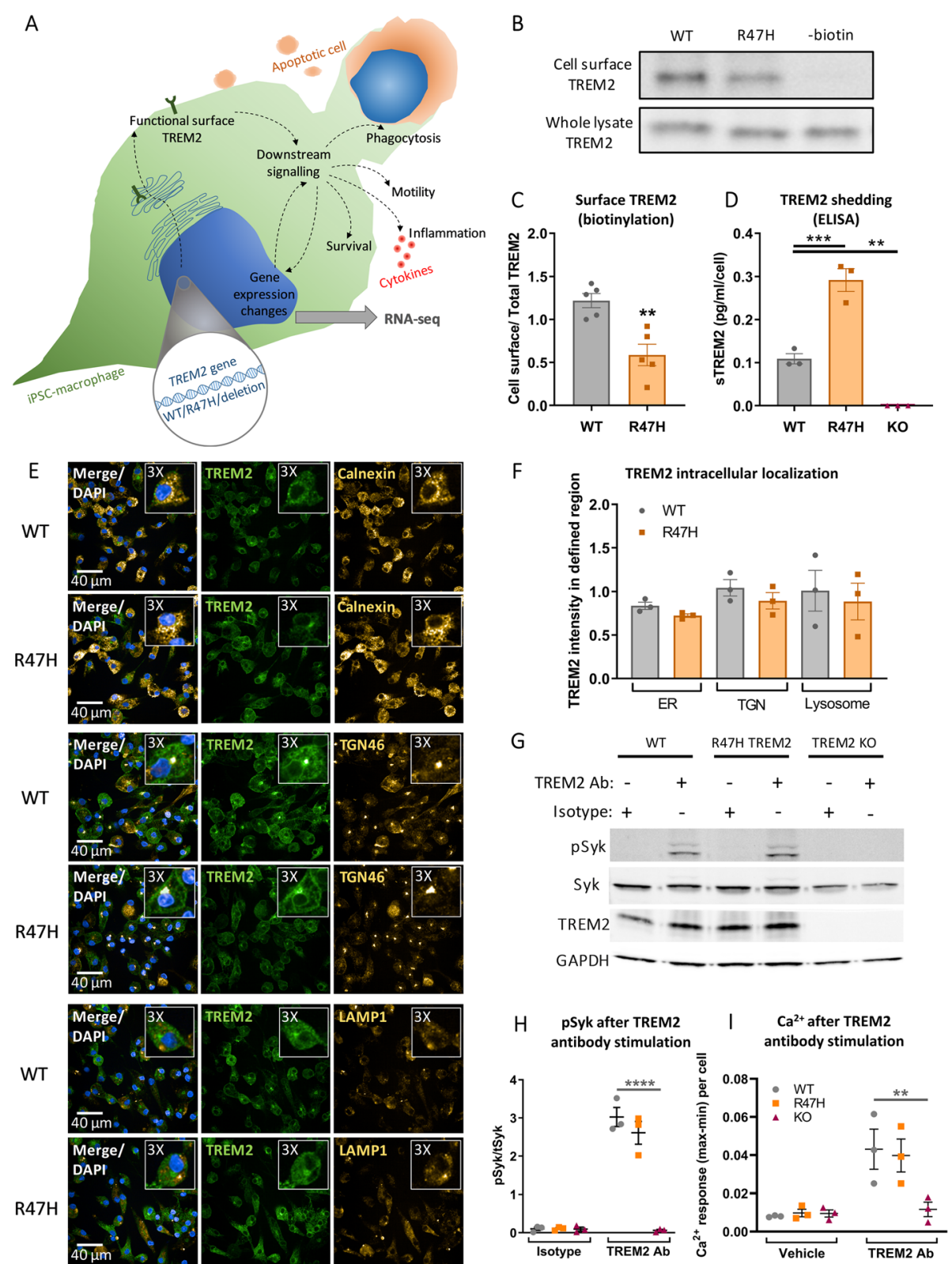

Fig. 1 (See legend on next page.) 


\section{(See figure on previous page.)}

Fig. 1 Reduced cell surface localization of R47H TREM2 does not impair antibody-mediated activation of TREM2 in pMac. a Schematic of microglia phenotypes investigated in this study. $\mathbf{b}$, c Reduced cell surface expression of R47H TREM2. Cell surface proteins on pMac were biotinylated and pulled down, the level of TREM2 protein enrichment was measured by Western blotting vs whole cell lysate, probed on separate blots. c Means \pm SEM, for $N=5$ harvests measured on separate Western blots. 2-tailed paired t-test: ** $p=0.0011$ for R47H versus WT. d Increased sTREM2 production from R47H TREM2 pMac. sTREM2 were measured from unstimulated pMac supernatants by ELISA. Means $\pm S E M$, for $N=3$ harvests measured on same ELISA plate, data for each harvest was normalised to the average cell count. 1-way ANOVA, with Dunnett's post hoc test: $p=0.0005 \mathrm{R} 47 \mathrm{H}$ versus WT $\left(^{* *}\right), p=0.0066 \mathrm{KO}$ versus WT $\left({ }^{* *}\right)$. e, $\mathbf{f}$ Co-localization of TREM2 with subcellular compartment markers in fixed and permeabilized pMac, images are a confocal slice at $4 \mu \mathrm{m}$, taken with Opera Phenix microscope. Inset panels are $\times 3$ magnification of a selected cell. Calnexin used as a marker for ER, TGN46 for TGN, and LAMP1 for lysosomes. f Co-localization expressed as a ratio of TREM2 intensity to compartment marker intensity, in regions automatically segmented by high marker staining. Means $\pm \mathrm{SEM}$, for $N=3$ harvests, each in triplicate wells. 2-way ANOVA, with Bonferroni's post hoc test, no significant differences. $\mathbf{g}$, $\mathbf{h}$ TREM2-activating antibody stimulation (used at concentration of $2.4 \mathrm{\mu g} / 1 \times 10^{6}$ cells and $3.84 \mathrm{\mu g} / \mathrm{mL}$, for $10 \mathrm{~min}$ ) of both WT and R47H TREM2 pMac caused SYK phosphorylation, measured by Western blotting. No response seen in TREM2 antibody-stimulated TREM2 KO cells, or cells treated with a goat lgG isotype control. $\mathbf{h}$ Means \pm SEM, for $N=3$ harvests measured on separate Western blots. 2-way ANOVA, with Sidak's post hoc test, pairwise comparisons to WT for each treatment: $p<0.001$ for KO stimulated with TREM2 Ab versus WT $(* * *)$. i Calcium response in response to TREM2 antibody is similar in WT and R47H TREM2 pMac, measured by peak Fluo4-AM fluorescence, normalised to minimum fluorescence and cell number. Means \pm SEM, for $N=3$ harvests. 2-way ANOVA, with Dunnett's multiple comparison test, pairwise comparisons to WT for each treatment: $p=0.0049$ for KO stimulated with TREM2 Ab versus $W T(* *)$

signature of early apoptosis [40]. Both fixed (dead) SHSY5Ys and synaptosomes were confirmed to expose surface phosphatidylserine, using annexin $\mathrm{V}$ staining (Additional file 1: Figs. S5, S6). An acid-sensitive dye, pHrodo iFL Red, was used to label the phagocytic cargoes to improve specific detection by high-content microscopy. Robust inhibition of the phagocytosis signal was achieved with actin inhibitors (cytochalasin D and jasplakinolide) and lysosome ATPase and autophagy inhibitor (bafilomycin A1), and significant enhancement by opsonising the cargo with human serum (Additional file 1: Figs. S5, Fig. S6). This demonstrates that the assay is sufficiently sensitive to discriminate alterations in phagocytic capability. Addition of recombinant annexin $\mathrm{V}$ to mask the exposed phosphatidylserine on the dead SH-SY5Ys led to a significant 30\% reduction in phagocytosis, indicating that a large proportion of phagocytosis may be phosphatidylserineindependent (Additional file 1: Fig. S5).

The involvement of TREM2 in phagocytosis was investigated by performing ICC for TREM2 on control pMac phagocytosing pHrodo-labelled dead SH-SY5Ys. Strikingly, TREM2 was observed to be strongly concentrated at pMac phagocytic cups (Fig. 2a). Internalised SHSY5Ys in RAB9+ endosomes had weak TREM2 signal, as would be expected for a phagocytic receptor that is quickly recycled back to the plasma membrane (Fig. 2b). TREM2 KO pMac had a $63 \%$ and 55\% reduction in phagocytosis of dead SH-SY5Ys and synaptosomes respectively (Fig. 2c-f), in relation to the quantity of cargo consumed over $5 \mathrm{~h}$ (measured as average spots per well), indicating that these processes require TREM2. Additionally, a lower proportion of the TREM2 KO pMac phagocytosed dead SH-SY5Ys. With respect to synaptosome phagocytosis, the proportion of macrophages taking up cargo was saturated very quickly and therefore was not significantly reduced in the TREM2 KO line, likely due to the small size of the cargo (approximately $1.5 \mu \mathrm{m}$, measured by electron microscopy in Fig. S6, Additional file 1). In contrast, the $\mathrm{R} 47 \mathrm{H}$ mutation of TREM2 did not significantly impair phagocytosis of dead SH-SY5Ys or synaptosomes, in fact there appeared to be an enhancement of synaptosome phagocytosis (Fig. 2f). Addition of dead SH-SY5Ys to the pMac in a timecourse, with an unstimulated control for each timepoint, produced a strong SYK phosphorylation signal in the WT line peaking around $30 \mathrm{~min}$ (Fig. $2 \mathrm{~g}$ ). SYK phosphorylation was not significantly different in the $\mathrm{R} 47 \mathrm{H}$ line; however, the TREM2 KO had a significant $64 \%$ decrease in peak SYK phosphorylation relative to WT (Fig. 2h). The SYK phosphorylation response of the pMac to dead SH-SY5Ys is consistent with the levels of phagocytosis measured. Together, the data shows that recognition and engulfment of neuronal material by pMac is partially TREM2-dependent and that the $\mathrm{R} 47 \mathrm{H}$ TREM2 mutant has no significant defect in this regard.

\section{Altered morphology of TREM2 KO pMac is not mirrored by R47H pMac}

Altered morphology of the TREM2 KO pMac relative to the WT line was consistently observed during measurements of phagocytosis. From the phagocytosis negative control images of pMac, with cytosolic and nuclear fluorescent stains, two-dimensional cell morphological parameters were calculated using Columbus software. TREM2 KO pMac were significantly smaller and rounder than WT pMac, whereas R47H TREM2 pMac were not significantly different to the WT (Fig. 3a, b).

\section{Directed migration is impaired in TREM2 KO but not R47H pMac}

Migration defects have been previously identified in TREM2 KO mice, with Ccl2, C5a, or apoptotic neurons 

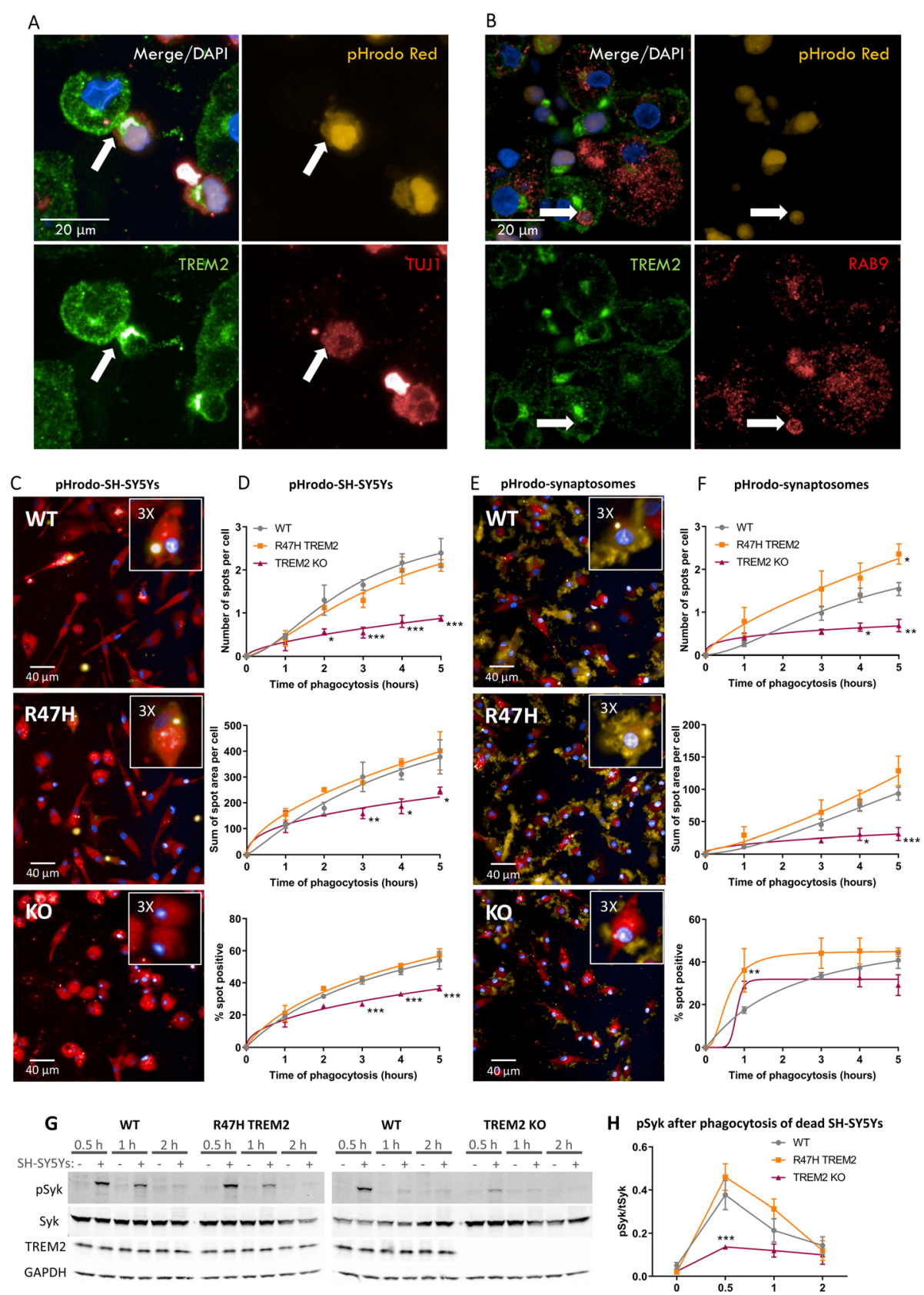

Fig. 2 Phagocytosis of dead SH-SY5YS and synaptosomes is reduced in TREM2 KO, but not R47H TREM2, relative to WT pMac. a After $3 \mathrm{~h}$ of phagocytosis of pHrodo-labelled dead SH-SY5Y, immunofluorescence staining shows that TREM2 is highly recruited to the phagocytic cup (marked by white arrow) during engulfment of cells expressing the neuronal marker TUJ1, whereas in $\mathbf{b}$ TREM2 is lost before maturation to RAB9+ endosomes (marked by white arrow). c-f Phagocytosis is impaired in TREM2 KO pMac only. Representative images of phagocytosis of SHSY5Ys (c) or synaptosomes (e) shown in yellow, by pMac (red cytoplasm and blue nucleus), taken at $3 \mathrm{~h}$ with INCell 6000. Inset is a section of the image magnified 3-fold. $\mathbf{d}$, $\mathbf{f}$ Means were quantified for the parameters: number of spots per cell, sum of spot areas $\left(\mu \mathrm{m}^{2}\right)$ per cell, percentage of cells containing phagocytosed particles per field. Data was normalised to mean for each genotype per experiment. Means \pm SEM, for $N=3$ harvests. Repeated-measures 2-way ANOVA, Dunnett's post hoc test, pairwise comparisons to the WT for each time: ${ }^{*} p<0.05$, ${ }^{* *} p<0.01,{ }^{* * *} p<$ 0.001. g, h Phagocytosis of dead SH-SY5Ys results in SYK phosphorylation, which is unaffected in R47H TREM2 cells but attenuated in TREM2 KO line, measured by Western blotting at $0.5,1$, and $2 \mathrm{~h}$ after phagocytosis initiation. $\mathbf{h}$ Means $\pm \mathrm{SEM}$, for $\mathrm{N}=3$ harvests. Repeated-measures 2 -way ANOVA, with Dunnett's post hoc test, pairwise comparisons to the WT for each time: $p=0.0008$ at $0.5 \mathrm{~h}$ stimulation for KO versus WT (***) 


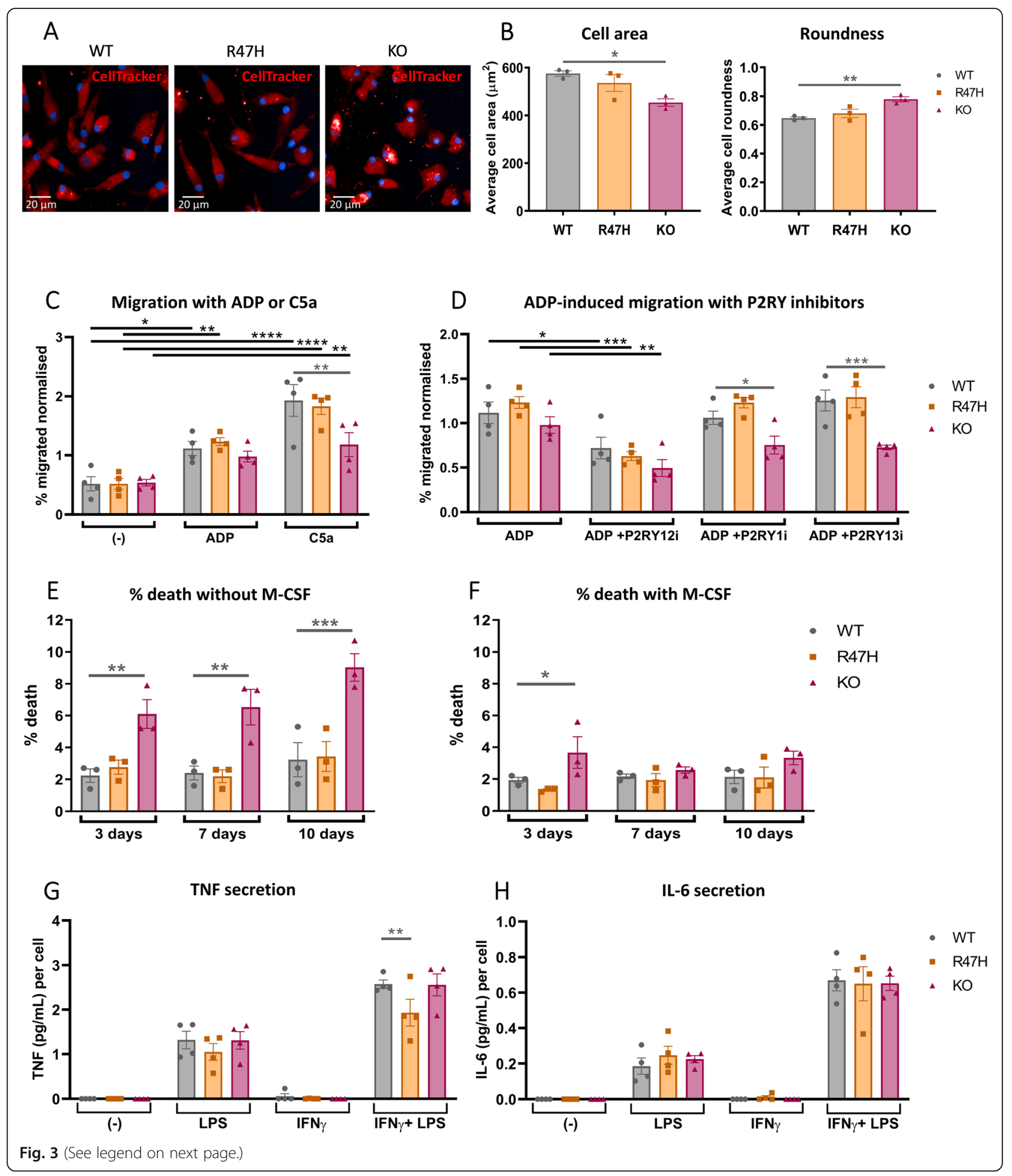


(See figure on previous page.)

Fig. 3 Divergent phenotypes in TREM2 KO and R47H TREM2 pMac, regarding cell morphology, migration, survival, and inflammatory responses. a, b TREM2 KO pMac are smaller and rounder than WT. Cell morphology measured by microscopy of pMac stained with CellTracker Deep Red, cells were fixed and imaged on INCell 6000 microscope. Representative images shown (a), and mean cell area $\left(\mu \mathrm{m}^{2}\right)$ and roundness were automatically quantified from 9 fields per well in triplicate wells using Columbus software (b). Means $\pm \mathrm{SEM}$, for $N=3$ harvests. 1-way ANOVA with Dunnett's post hoc test: $p=0.019$ for cell area in KO versus WT $(*), p=0.007$ for roundness in KO versus WT $(* *)$. c, d TREM2 KO pMac migrate slower towards C5a, but not ADP, compared with WT. Cell migration measured by transwell assay. Migration of pMac towards $30 \mu \mathrm{M}$ ADP or $3 \mathrm{nM} \mathrm{C5a}$ is compared to unstimulated migration over $6 \mathrm{~h}(\mathbf{c})$, and inhibitors used to unmask the contribution of purinergic receptors

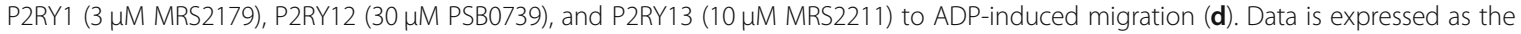
percentage of migrated cells and was normalised to average migration for the harvest. Means \pm SEM, for $N=4$ harvests. 2-way ANOVA with Dunnett's post hoc test. Black annotations compare stimulation to unstimulated control, or ADP + purinergic inhibitors to the ADP-only control. Grey annotations compare R47H or KO versus WT for each stimulation. ${ }^{*} p<0.05$, ${ }^{* *} p<0.01,{ }^{* * *} p<0.001$, **** $p<0.0001$, all unannotated comparisons are not significant. e, $\mathbf{f}$ TREM2 KO pMac exhibit increased cell death in the absence of M-CSF, whereas WT and R47H pMac remain viable. Survival after M-CSF withdrawal measured at 3, 7, and 10 days, with a comparison between M-CSF-deficient condition (e) to full-media controls (f) in the same plate. Means \pm SEM, for $N=3$ harvests. Repeated-measures 2-way ANOVA, with Dunnett's post hoc test, pairwise comparisons to WT for each time: M-CSF-deficient KO versus WT at 3 days $p=0.0051\left(^{(*)}\right.$ ), at 7 days $p=0.003\left(^{* *}\right)$, and at 10 days $p=0.0001\left({ }^{* * *}\right)$. Full media KO versus WT at 3 days $p=0.035\left(^{*}\right) . \mathbf{g}$, $\mathbf{h}$ Comparable secretion of TNF and IL-6 by pMac in response to E. coli LPS (100 $\left.\mathrm{ng} / \mathrm{mL}, 4 \mathrm{~h}\right) \pm$ priming by interferon- $\gamma(100 \mathrm{ng} / \mathrm{mL}$, $24 \mathrm{~h}$ prior to LPS). Concentration of TNF ( $\mathbf{g})$ and IL-6 (h) was measured by separate ELISAs of the same supernatants, normalised to cell number, and normalised to the average $\mathrm{pg} / \mathrm{mL} /$ cell for the harvest. Means $\pm \mathrm{SEM}$, for $N=4$ harvests. 2-way ANOVA, with Dunnett's post hoc test, pairwise comparisons to WT for each stimulation: $p=0.0097$ for TNF secreted from R47H versus WT with LPS \pm IFNy stimulation $\left(^{* *}\right)$. As expected, IFNy-priming enhances TNF and IL-6 secretion upon LPS stimulation, significance is not depicted for clarity, but $p<0.001$ for IFN + LPS versus LPS, for TNF and IL-6 of all genotypes

as chemotactic stimuli [45]. Migration of pMac was measured by plating into transwell inserts with $5-\mu \mathrm{m}$ pores, and after $6 \mathrm{~h}$, the percentage of cells that had moved to the underside of the inserts was measured. Migration increased in a dose-dependent manner with ADP or C5a spiked into media below the transwells (Additional file 1: Fig. S7; Fig. 3c). ADP, released by apoptotic cells, causes mainly chemokinesis, whereas $\mathrm{C} 5 \mathrm{a}$ is a potent chemotaxis inducer $[46,47]$. In the TREM2 KO pMac, ADP caused a similar increase migration to the WT (Fig. 3c). However, C5a-stimulated migration was significantly impaired, with an average reduction of $40 \%$ (Fig. 3c). The R47H TREM2 cells had no impairment of ADP-induced or C5a-induced migration (Fig. 3c). Interestingly, further investigation of ADPstimulated migration with $\mathrm{P} 2 \mathrm{Y}$ receptor inhibitors revealed that TREM2 KO pMac rely upon multiple P2Y receptor sub-types for ADP detection, whereas the WT and R47H lines mainly require P2RY12 activity (Fig. 3d). Selective inhibition of P2RY12 receptors by PSB0739 reduced ADP-stimulated migration in all genotypes, but a P2RY1 inhibitor (MRS2179) and a P2RY13 inhibitor (MRS2211) reduced migration of only TREM2 KO cells. RNA-seq can help to explain this phenomenon: transcription of P2RY1 and P2RY13 was significantly increased in unstimulated TREM2 KO pMac relative to the WT (Fig. 5b), whereas P2RY12 was not differentially expressed. Despite upregulated purinergic receptor expression, the TREM2 KO cells had similar ADPstimulated migration to the WT, suggesting that increased ADP detection is counterbalanced by a generalised motility defect. Taken together, the data suggests defective migration in TREM2 $\mathrm{KO}$ pMac, whereas the
R47H TREM2 pMac had similar migration to the WT under all conditions tested.

\section{Survival after M-CSF withdrawal is impaired in TREM2 KO but not $\mathrm{R} 47 \mathrm{H}$ pMac}

TREM2 activates AKT and $\beta$-catenin-mediated prosurvival signalling and is proposed to have tonic activity in the absence of any specific damage-associated or pathogenassociated signals $[5,48]$. The growth factor M-CSF, used for macrophage differentiation, stimulates the same prosurvival signalling pathways and therefore could compensate for TREM2 deficiency unless depleted. After 7 days of differentiation with M-CSF, M-CSF was withdrawn from pMac by a full media change, and cell death analysed after a further 3-10 days in comparison to complete media. Interestingly, WT and R47H TREM2 pMac did not lose viability in response to $\mathrm{M}$-CSF withdrawal, even after 10 days (Fig. 3e). There was a small but significant enhancement of cell death following M-CSF withdrawal in TREM2 $\mathrm{KO}$ pMac that increased over time. In full media, there was little change in viability over time (Fig. 3f); therefore, cell death was largely driven by M-CSF withdrawal.

\section{LPS-induced inflammation is not strongly perturbed in TREM2 KO or R47H pMac}

TREM2 deficiency has been reported to potentiate bacterial lipopolysaccharide (LPS)-induced inflammation in mouse bone marrow-derived macrophages, but not human microglia-like cells [49-51]. Challenge with E. coli LPS dosedependently upregulated secretion of the proinflammatory cytokines TNF and IL-6, in pMac from all three genotypes (Additional file 1: Fig. S7). Only at the highest dose of LPS, the TREM2 KO line produced significantly less TNF than 
the WT line, whereas IL-6 secretion was unaltered. When the pMac were primed with IFNY for $24 \mathrm{~h}$ before stimulation with LPS (Fig. 3g, h), clear potentiation of TNF and IL-6 responses was observed as expected [50]. Here, cytokine secretion of the TREM2 KO cells was unchanged versus the WT line, whereas in the R47H TREM2 line there was a significant (25\%) reduction of TNF secretion. Together, these results suggest that TREM2 expression is not acting as a brake on inflammation in pMac.

RNA sequencing reveals shared transcriptional signature of the TREM2 KO and R47H TREM2

Although no gross phenotypic abnormalities were detected in the R47H TREM2 pMac, more subtle effects of the mutation upon cell processes would be signposted in the transcriptional signature. We performed RNA sequencing (RNA-seq) of unstimulated pMac from three consecutive weeks of harvests, comparing the TREM2 $\mathrm{KO}$ and $\mathrm{R} 47 \mathrm{H}$ lines with WT. We firstly confirmed the microglial identity of the cells by comparing their transcriptome with data from Abud et al., who used cells of myeloid lineages including primary microglia and iPSCmicroglia-like cells (Fig. 4a) [42]. Our pMac cluster closely with the Abud et al. iPSC-microglia-like cells, and their TREM2 genotype has no effect on clustering in this context; instead, there is a little separation by differentiation age. Our pMac, which are not exposed to exogenous TGF $\beta$, are most similar to the Abud et al.

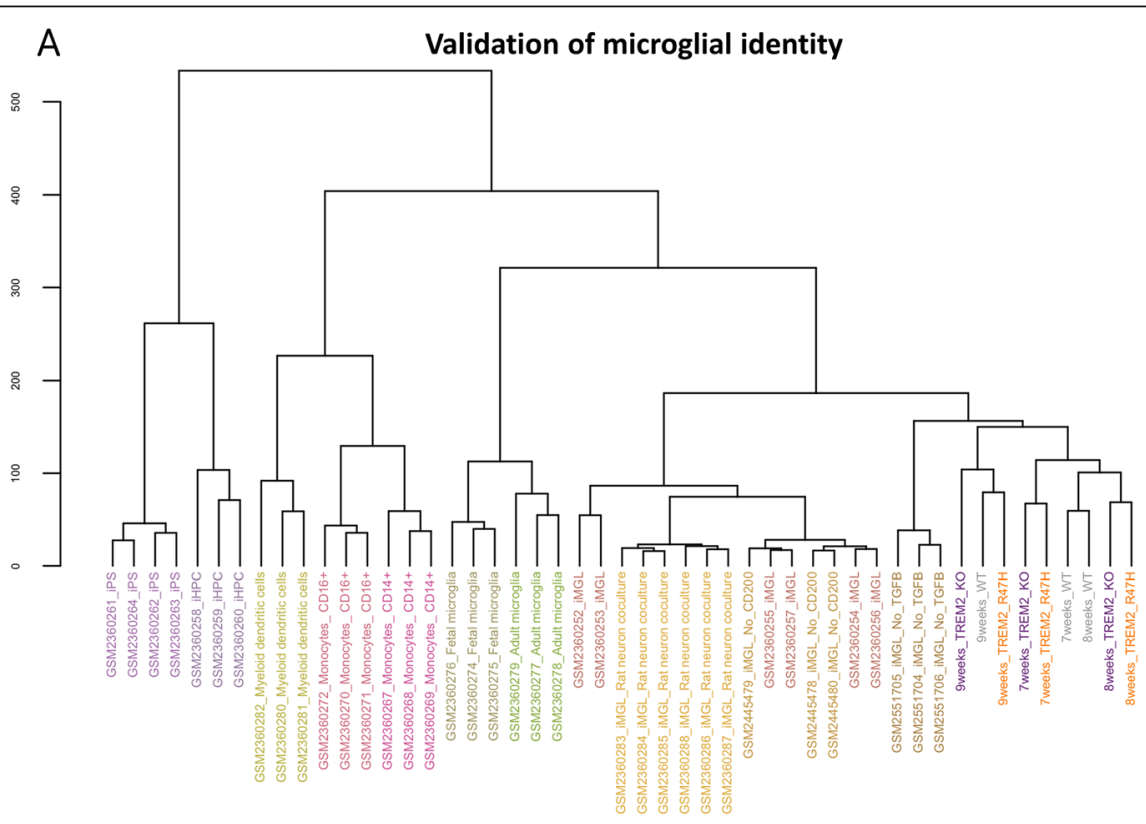

\section{B PC1 vs PC2}

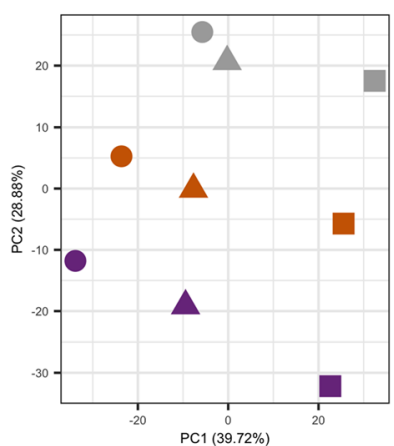

C DEG overlap between R47H and KO
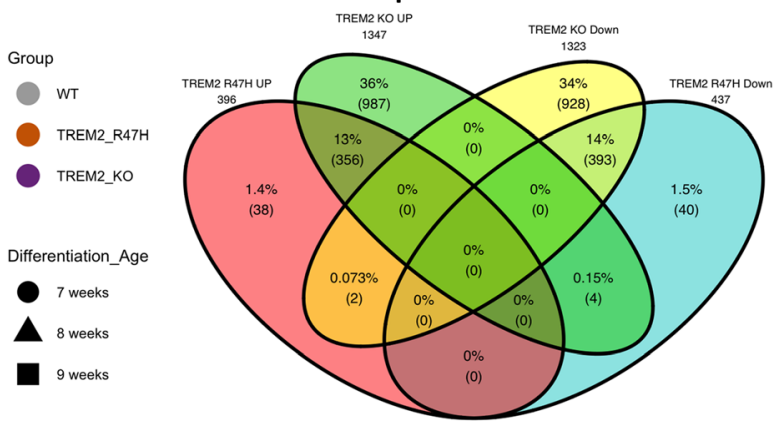

Fig. 4 Transcriptomics reveal high overlap in dysregulated genes of R47H TREM2 and TREM2 KO pMac, relative to WT. a Validation of pMac "microglial identity" by dendrogram comparison to Abud et al. transcriptomes of iPS cells, iPSC-haematopoietic progenitor cells (iHPC), iPSCmicroglia-like cells (iMGL), iMGL without TGF 31 or without CD200 supplementation, iMGL co-cultured with rat cortical neurons, blood-derived monocytes, blood-derived dendritic cells, and primary foetal and adult human microglia [42]. b Plot of principal component analysis (PCA) with the first two principal components separating the RNA-seq samples by differentiation age and genotype. Ages represented by shapes, and genotypes represented by colour. $\mathbf{c}$ Venn diagram of differentially expressed genes (DEGs) identified relative to the WT line, showing the overlap between R47H TREM2 and TREM2 KO DEGs. DEGs are separately categorised as "upregulated" or "downregulated" relative to the WT 
samples with TGF $\beta$ withdrawal. Next, we performed principal component analysis to identify sources of transcriptional variation. Interestingly, the differentiation age of the cells harvested at weekly intervals accounted for nearly $40 \%$ of the variation on PC1, whereas TREM2 genotype accounted for $29 \%$ of the variation (PC2) (Fig. 4b). On a PCA plot of PC1 versus PC2, the samples are ordered along the PC2 axis as KO-R47H-WT, showing clearly that the $\mathrm{R} 47 \mathrm{H}$ mutation has an intermediate transcriptional impact in comparison to TREM2 KO. It is also clear that strong age-related changes in gene expression could be confounding; therefore, PC1 was added as a covariate to the design formula for identifying differentially expressed genes.

Significantly differentially expressed genes (DEG) were then identified relative to the WT pMac (adjusted $p$ value $<0.05$ ), with 2670 in the TREM2 $\mathrm{KO}$ versus WT and 833 in the R47H TREM2 versus WT. Top DEGs for TREM2 $\mathrm{KO}$ and $\mathrm{R} 47 \mathrm{H}$ are illustrated as volcano plots in the supplementary data (Additional file 1: Fig. S8), and as a heatmap in Fig. 5a, with the inclusion of some extra DEGs selected for their relevance to cell motility and adhesion. A Venn diagram shows that $90 \%$ of DEGs identified in the R47H TREM2 line are also differentially expressed in the TREM2 KO, with the same direction of regulation (Fig. 4c). Only 6 of the 833 R47H TREM2 DEGs are regulated in a different direction to the TREM2 KO: CHCHD2, THRB, ZNF248, and TRIM4 are down in the R47H and up in the KO; ST3GAL1 and S100A1 are up in the R47H and down in the KO. Gene ontology (GO) analysis for $\mathrm{KO}$ and $\mathrm{R} 47 \mathrm{H}$ DEGs revealed enrichment for immunity, inflammation, proliferation, migration, and adhesion (Additional file 1: Fig. S8). To further explore the dysregulated functional pathways, we performed an unbiased Louvain clustering of the TREM2 KO DEGs in protein-protein interaction (PPI) networks, to identify 5 different modules of functionally related genes, and identified the top 10 most enriched GO terms for each group (Fig. 5b). Group 1 is the largest group and associated with immune responses, cellmatrix adhesion, migration, proliferation, endocytosis, and exocytosis. Group 2 is associated with metabolic processes including lipid and carbohydrate metabolism and also includes autophagy. Group 3 is associated with cell division, whereas group 4 is associated with actin organisation and GTPase and kinase regulation. Group 5 is small and includes terms for chemotaxis and calcium ion homeostasis. We then overlaid the R47H TREM2 DEGs that overlap with TREM2 KO onto the same PPI groups, in order to determine whether the $\mathrm{R} 47 \mathrm{H}$ dysregulated genes are spread over many GO terms or confined to a single biological process (Fig. 5b). The results confirmed that the R47H DEGs hit almost every biological process that the TREM2 KO DEGs target, and therefore that the $\mathrm{R} 47 \mathrm{H}$ mutation causes a partial loss of function of TREM2.

\section{Cell adhesion to extracellular matrix is dysregulated by $\mathrm{R} 47 \mathrm{H}$ TREM 2 and TREM $2 \mathrm{KO}$, and role of TGF- $\beta 1$ was investigated}

Transcript levels of selected adhesion-related DEGs were validated by qRT-PCR, using four harvests of pMac from another differentiation, compared directly with samples of extracted RNA used for the RNA-seq (three harvests). There was strong overlap between the original RNA-seq samples (open symbols) and samples obtained subsequently (filled symbols), for all of the genes: ITGB3, ITGB5, ITGAV, FN1, LAMB2, SDC4, and GPC4 (Fig. 6a). ITGB3, ITGB5, SDC4, and GPC4 were significantly downregulated in both the $\mathrm{R} 47 \mathrm{H}$ and $\mathrm{KO}$ pMac. ITGAV was significantly downregulated in the $\mathrm{KO}$ but not $\mathrm{R} 47 \mathrm{H}$ pMac. $L A M B 2$ was significantly upregulated in both the $\mathrm{R} 47 \mathrm{H}$ and KO pMac. FN1 was not significantly downregulated in this experiment, but in an independent follow-up assay, there was a significant reduction in TREM2 KO pMac (Fig. 6b).

We then used the Ingenuity Pathways Analysis (IPA) platform to search for common predicted upstream regulators, within each of the previously identified functionally related modules. Due to the large size of group 1 module and its relevance to migration and adhesion phenotypes, we were particularly interested in top hits for group 1, shown in Tables 2 (inhibitory) and 3 (activatory). The group 1 top hits predicted to inhibit the TREM2 KO transcriptional signature included TGF $\beta 1$ (Table 2). TGF $\beta 1$ is a growth factor commonly used for maintenance of primary microglia and of iPS-microglialike cell cultures $[42,52]$, but not included in our culture. We stimulated pMac with recombinant human TGF $\beta 1$ for $24 \mathrm{~h}$, to assess whether TGF $\beta 1$ could "rescue" expression of the aforementioned selected genes (Fig. 6b). TGF $\beta 1$ treatment strongly induced expression of ITGB3 and ITGAV, effectively rescuing the effect of the TREM2 mutations. TGF $\beta 1$ also diminished $L A M B 2$ expression in TREM2 KO pMac, although not down to the same level as WT. However, the other genes were either unaffected by TGF $\beta 1$ (CHCHD2, FN1, SDC4), or downregulated in the WT line, mimicking the TREM2 mutations (ITGB5, GPC4).

Since TGF $\beta 1$ was predicted to oppose some of the transcriptional changes wrought by TREM2 KO, we hypothesised that TREM2 KO pMac are expressing less TGF $\beta 1$ protein than WT and that loss of TGF $\beta 1$ may mediate cell dysfunction in TREM2 KO pMac. TGF $\beta 1$ transcripts are not significantly downregulated in the RNA-seq. However, TGF $\beta 1$ protein secretion from pMac, measured by ELISA, is significantly reduced in 
A Heatmap of DEGs

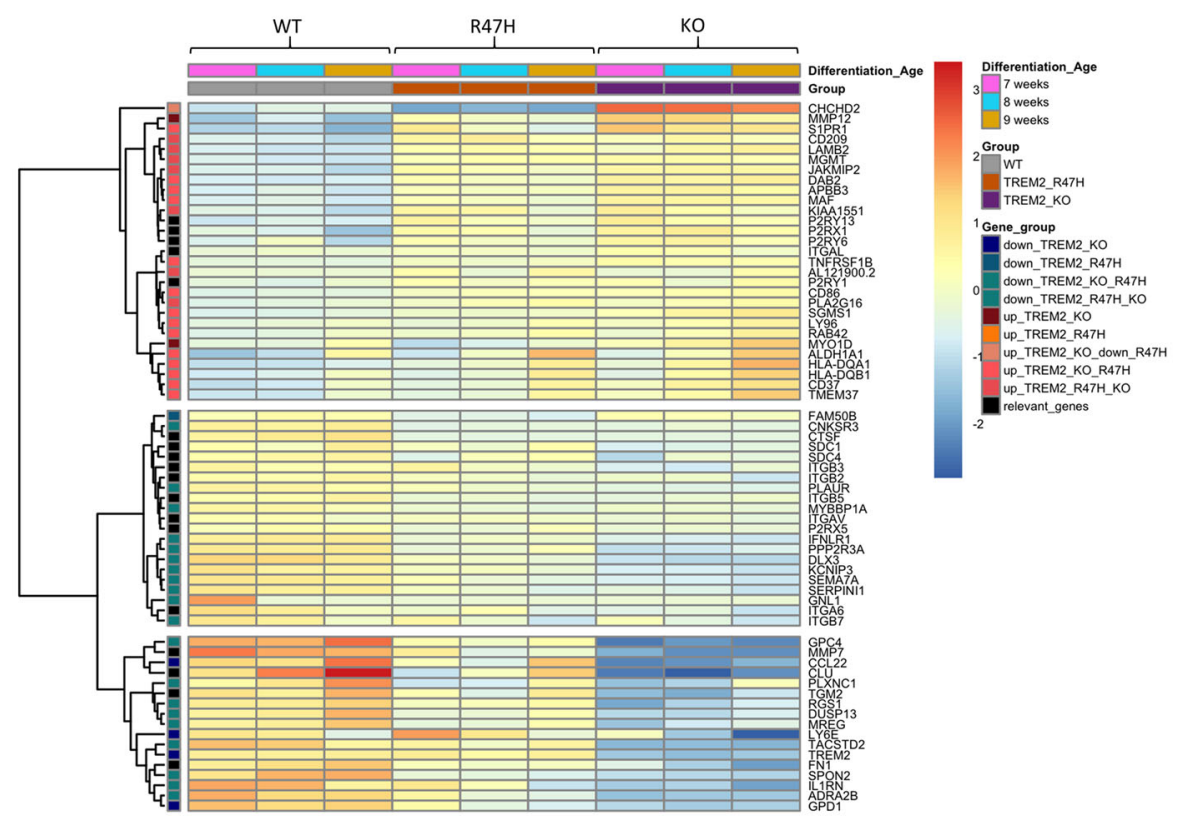

B

GO terms for PPI groups

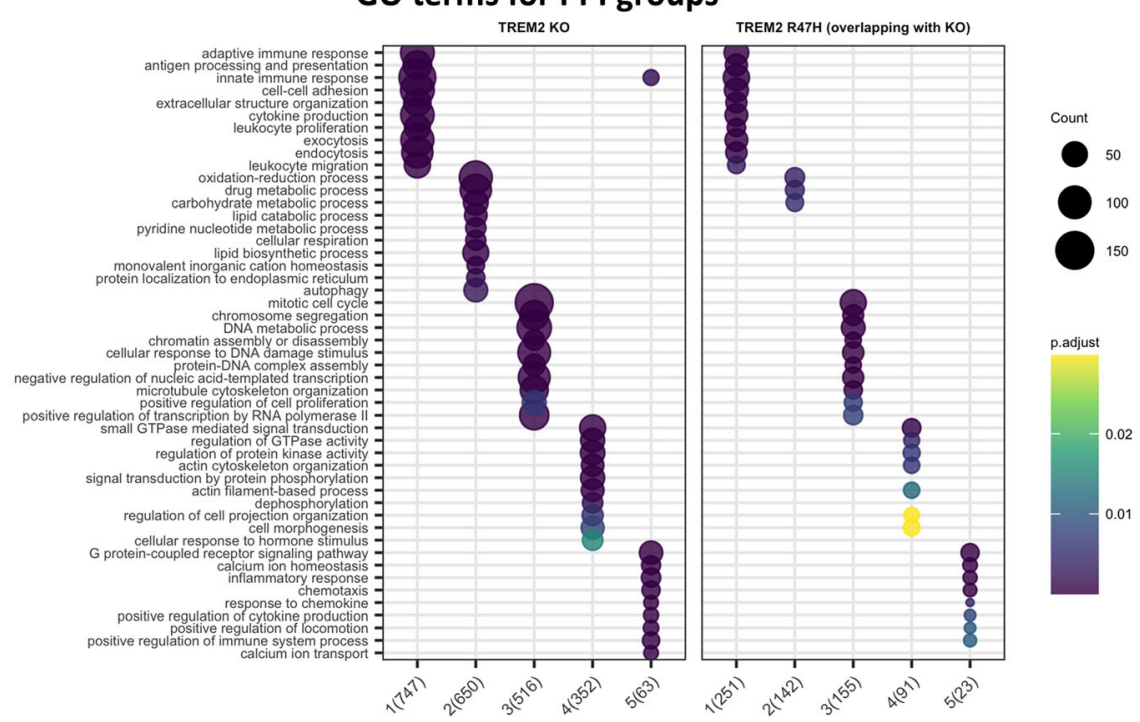

Fig. 5 Top DEGs of R47H TREM2 and TREM2 KO pMac overlap; furthermore, the R47H DEGs that are shared with TREM2 KO represent numerous biological processes, distributed between five protein-protein interaction (PPI) modules. a Heatmap of top upregulated and top downregulated DEGs for R47H TREM2 and TREM2 KO, with the relative expression for each gene represented by colours on the corresponding row. A selection of "relevant genes" was also included. Unbiased clustering (dendrogram on the left) shows that genes separate into two major clusters based on whether they are upregulated or downregulated in TREM2 KO or R47H TREM2, and there is no genotype-specific segregation. $\mathbf{b}$ Five modules of functionally related DEGs identified by PPI network analysis of TREM2 KO DEGs, with enriched gene ontology (GO) terms shown. R47H DEGs were only included where they were also differentially expressed in TREM2 KO and were overlaid onto clusters identified using TREM2 KO data. Clusters identified numerically on the $x$-axis, with TREM2 KO on the left and R47H TREM2 on the right, showing a similar pattern of dysregulated cell functions. Number of DEGs represented by circle size, and $p$ value represented by colour

TREM2 KO pMac relative to the WT (Fig. 6c). The R47H pMac do not have significantly different TGF $\beta 1$ secretion to WT. Furthermore, incubation with a SYK inhibitor mimicked the effect of TREM2 KO (Fig. 6c), which suggests that reduced SYK activation in TREM2 KO pMac could reduce TGF $\beta 1$ expression.

Next, we looked to validate protein expression for FN1, ITGAV, ITGB3, and ITGB5, which encode 

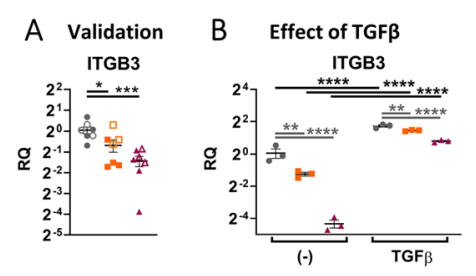

C
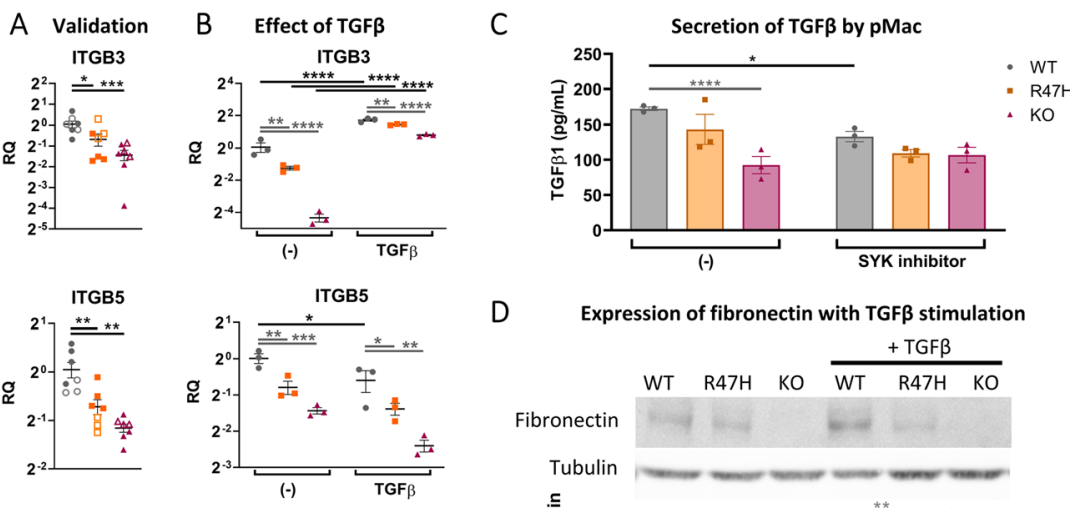

D

Expression of fibronectin with TGF $\beta$ stimulation

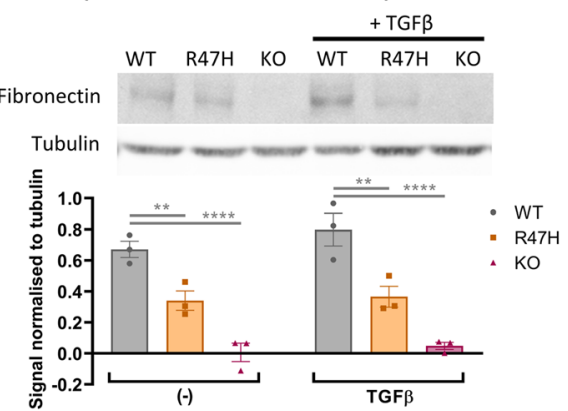

E Surface expression of integrins with TGF $\beta$ stimulation
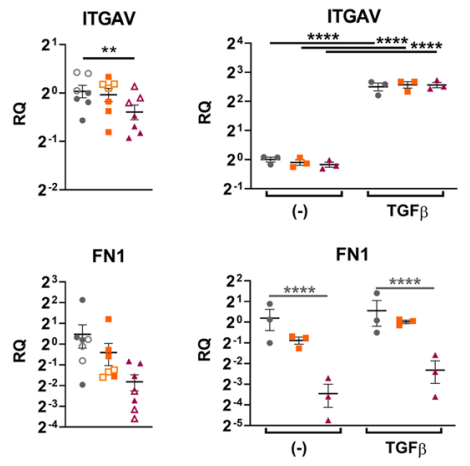
$\alpha \mathbf{V} \beta 3$
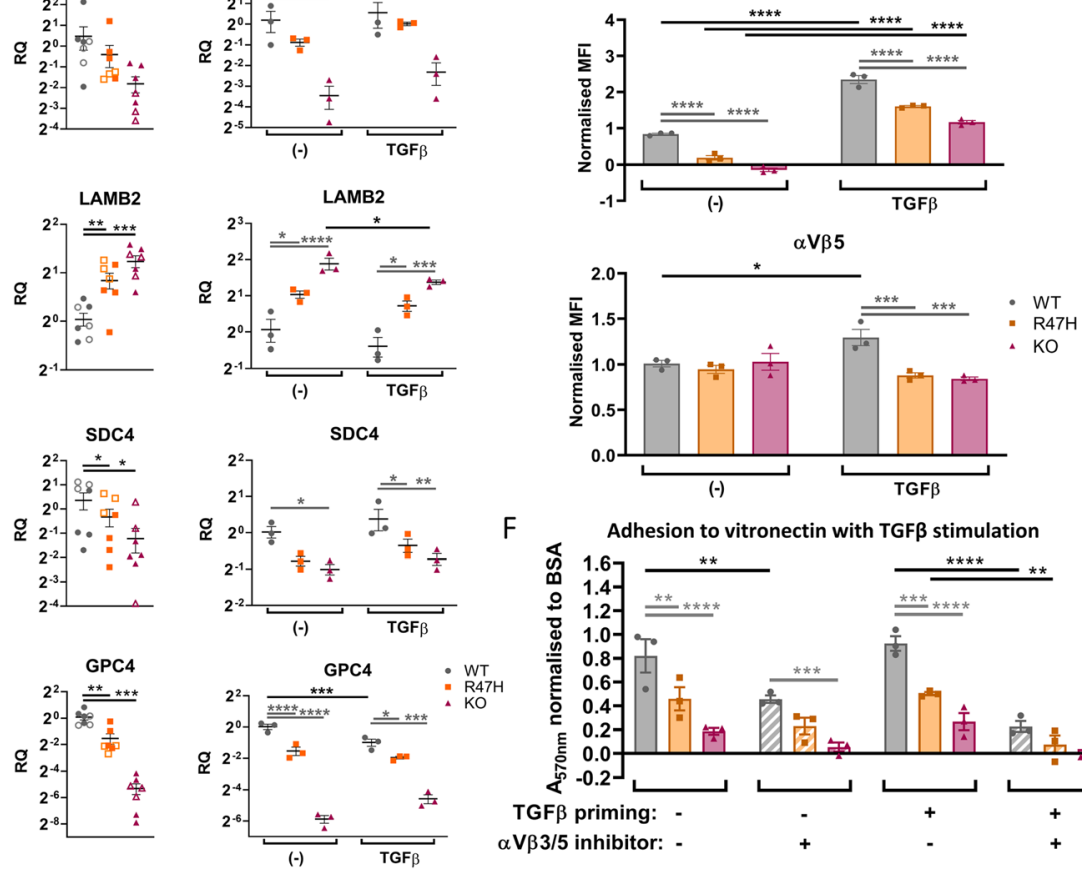

$F \quad$ Adhesion to vitronectin with TGF $\beta$ stimulation

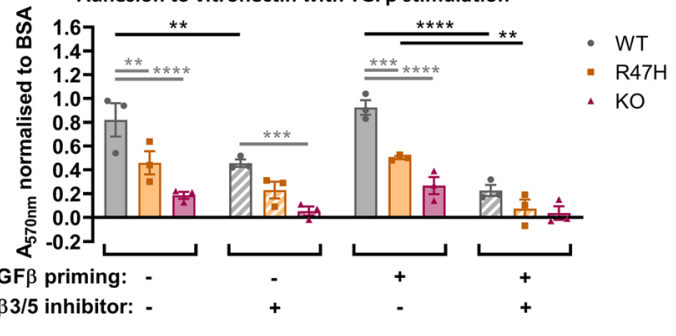

Fig. 6 (See legend on next page.) 
(See figure on previous page.)

Fig. 6 Extracellular matrix-adhesion modifiers and adhesion to vitronectin are dysregulated in R47H TREM2 and TREM2 KO pMac. TGF $\beta$ treatment does not rescue adhesion deficits. a Validation of selected RNA-seq hits by qRT-PCR of unstimulated pMac. Means \pm SEM, for $N=7$ harvests, including the 3 samples originally used for RNA-seq (open symbols) plus 4 samples harvested independently from a separate differentiation (filled symbols). Repeated-measures 1-way ANOVA, with Dunnett's post hoc test, pairwise comparisons to the WT. $\mathbf{b}$ Effect of TGF $\beta$-stimulation (50 ng/ $\mathrm{mL}, 24 \mathrm{~h}$ ) on mRNA levels of selected RNA-seq hits, measured by qRT-PCR. Means $\pm \mathrm{SEM}$, for $N=3$ samples harvested independently to Fig. 5 a. Two-way ANOVA, with Sidak's post hoc test. c TREM2 KO pMac secrete reduced levels of TGF $\beta 1$ compared with WT, and TGF $\beta 1$ secretion is partly SYK-dependent. Total (inactive and active) TGF $\beta 1$ measured from supernatants by ELISA, cells treated \pm OXSI- $2(2 \mu M, 24 \mathrm{~h})$ to inhibit SYK. Means $\pm \mathrm{SEM}$, for $N=3$ harvests. Two-way ANOVA, with Sidak's post hoc test. $\mathbf{d}$ Fibronectin protein expression is reduced in both R47H TREM2 and TREM2 KO versus WT. Fibronectin measured by Western blotting of pMac \pm TGF $\beta 1$ stimulation $(50 \mathrm{ng} / \mathrm{mL}, 24 \mathrm{~h})$. Means \pm SEM, quantified for $N=$ 3 harvests on separate blots. Two-way ANOVA, with Sidak's post hoc test. TGF $\beta 1$ vs unstimulated was not significant. e aV $\beta 3$ complex formation is reduced in both R47H TREM2 and TREM2 KO versus WT. Intact surface integrins aV 33 and aV 35 measured by flow cytometry in pMac \pm TGF 31 stimulation $(50 \mathrm{ng} / \mathrm{mL}, 24 \mathrm{~h}$ ). Data is expressed as the difference in median fluorescence intensity of the specific antibody versus isotype control, normalised (by subtraction) to the average for the harvest. Means \pm SEM, for $N=3$ harvests. Two-way ANOVA, with Sidak's post hoc test. $\mathbf{f}$ Adhesion to vitronectin is reduced for both R47H TREM2 and TREM2 KO versus $\mathrm{WT}$, and treatment with TGF $\beta$ ( $50 \mathrm{ng} / \mathrm{mL}, 24 \mathrm{~h}$ prior to assay) increases aV $\beta 3 / 5$-dependent adhesion. Adhesion measured after $3 \mathrm{~h}$ by crystal violet colorimetric assay, and normalised to BSA-blocked wells (by division, and the result subtracted from 1). aV $33 / 5$ inhibitor (10 $\mu \mathrm{M}$ cilengitide) was added at the start of the assay to determine aV $33 / 5-s p e c i f i c$ adhesion to vitronectin (striped bars). Means \pm SEM, for $N=3$ harvests. Two-way ANOVA, with Dunnett's post hoc test. Black annotations compare stimulations to unstimulated control. Grey annotations compare R47H or $\mathrm{KO}$ versus WT for each condition. $\mathrm{WT}=$ grey circles, $\mathrm{R} 47 \mathrm{H}=\mathrm{orange}$ squares, TREM2 KO = burgundy triangles. ${ }^{*} p<0.05,{ }^{* *} p<0.01,{ }^{* * *} p<0.001,{ }^{* * * *} p<0.0001$, all unannotated comparisons are not significant

fibronectin, $\alpha \mathrm{V}$-integrin, $\beta 3$-integrin, and $\beta 5$-integrin respectively. Fibronectin protein was measured from whole-cell lysates by Western blotting and is significantly reduced in both R47H TREM2 and TREM2 KO pMac (Fig. 6d), consistent with the mRNA levels (Fig. 6b). Similarly, treatment of cells with recombinant TGF $\beta 1$ did not rescue fibronectin protein expression, which is consistent with the mRNA levels (Fig. 6b). Functional surface integrin complexes of $\alpha \mathrm{V} \beta 3$ and $\alpha \mathrm{V} \beta 5$ were detected by flow cytometry. Integrin $\alpha \mathrm{V} \beta 3$ was downregulated in R47H TREM2 pMac, relative to WT and was further downregulated in TREM2 KO pMac (Fig. 6e), consistent with the mRNA levels (Fig. 6a, b). Surprisingly, levels of $\alpha \mathrm{V} \beta 5$ in R47H TREM2 and TREM2 KO pMac were comparable to WT (Fig. 6e), despite having lower transcription of ITGAV and ITGB5 (Fig. 6a, b). We also tested the effect of TGF $\beta 1$ stimulation upon expression of $\alpha \mathrm{V} \beta 3$ and $\alpha \mathrm{V} \beta 5$ (Fig. 6e; Additional file 1: Fig. S9). TGF $\beta 1$ treatment for $24 \mathrm{~h}$ (50 ng/ $\mathrm{mL}$ ) caused dramatic upregulation of $\alpha \mathrm{V} \beta 3$ integrins at the cell surface, rescuing expression in the $\mathrm{R} 47 \mathrm{H}$
TREM2 and TREM2 KO pMac. Conversely, surface $\alpha \mathrm{V} \beta 5$ was upregulated by TGF $\beta 1$ only in the WT pMac and not in the R47H TREM2 and TREM2 KO pMac. Collectively the protein expression data for fibronectin, $\alpha \mathrm{V} \beta 3$, and $\alpha \mathrm{V} \beta 5$ largely agree with the transcriptional dysregulation identified by RNA-seq and qRT-PCR, but demonstrate that only $\alpha \mathrm{V} \beta 3$ is strongly upregulated by TGF $\beta 1$ stimulation.

Finally, we sought to ascertain whether TGF $\beta 1$ could rescue phenotypic defects of the TREM2 KO pMac. We hypothesised that $\alpha \mathrm{V} \beta 3$ expression would impact the adhesion of pMac to vitronectin. Mouse microglia adhere to vitronectin using the integrins $\alpha \mathrm{V} \beta 3$ and $\alpha \mathrm{V} \beta 5$, probably with contributions from other $\alpha \mathrm{V}$ integrins [53], and additionally the urokinase receptor (UPAR) may be involved [54]. Adhesion of pMac to vitronectin was measured by a 96-well plate colorimetric assay, and the contribution of $\alpha \mathrm{V} \beta 3 / 5$ integrins inhibited by treatment with cilengitide. Total vitronectin adhesion of unstimulated cells (Fig. 6f, first set of bars, between genotypes) was significantly reduced by $44 \%$ in R47H TREM 2 and

Table 2 Top 5 upstream regulators predicted to oppose TREM2 KO (group 1 genes)

\begin{tabular}{|c|c|c|c|c|c|}
\hline Name of regulator & Synonyms & Function & $\begin{array}{l}\text { Activation Z- } \\
\text { score }\end{array}$ & $\begin{array}{l}p \text { value of } \\
\text { overlap }\end{array}$ & $\begin{array}{l}\text { Number of group } 1 \\
\text { genes }\end{array}$ \\
\hline Dexamethasone & - & Corticosteroid drug & -2.66 & $1 \times 10^{-38}$ & 195 \\
\hline $\begin{array}{l}\text { Transforming growth } \\
\text { factor- } \beta\end{array}$ & TGFß1 & Growth factor & -2.55 & $7 \times 10^{-25}$ & 149 \\
\hline Filgrastim & $\begin{array}{l}\text { filgrastim-aafi, } \\
\text { filgrastim-sndz }\end{array}$ & Recombinant human G-CSF drug & -2.40 & $5 \times 10^{-22}$ & 62 \\
\hline Immunoglobulin & Ig, antibody & Adaptive immunity & -2.56 & $1 \times 10^{-16}$ & 69 \\
\hline $\begin{array}{l}\text { Mitogen activated protein } \\
\text { kinase } 1\end{array}$ & $\begin{array}{l}\text { MAPK1, ERK2, } \\
\text { p42MAPK }\end{array}$ & $\begin{array}{l}\text { Kinase downstream of growth factor } \\
\text { receptors }\end{array}$ & -2.89 & $2 \times 10^{-16}$ & 50 \\
\hline
\end{tabular}

Upstream regulators predicted by IPA to be inhibitory, ordered by lowest $p$ value 
Table 3 Top 5 upstream regulators predicted to mimic TREM2 KO (group 1 genes)

\begin{tabular}{|c|c|c|c|c|c|}
\hline Name & Synonyms & Function & $\begin{array}{l}\text { Activation } \\
\text { Z-score }\end{array}$ & $\begin{array}{l}p \text { value of } \\
\text { overlap }\end{array}$ & $\begin{array}{l}\text { Number of group } 1 \\
\text { genes regulated }\end{array}$ \\
\hline Interleukin-10 & IL10(A), CSIF, GVHDS, TGIF & Cytokine & +2.13 & $8 \times 10^{-22}$ & 60 \\
\hline Interleukin-27 & IL27(A), IL30, P38 & Cytokine & +2.57 & $2 \times 10^{-21}$ & 36 \\
\hline Fas receptor & $\begin{array}{l}\text { FAS, FasR, FASTM, ALPS1A, APO- } \\
\text { 1, APT1, CD95, TNFRSF6 }\end{array}$ & $\begin{array}{l}\text { Receptor for Fas ligand, initiates } \\
\text { apoptosis }\end{array}$ & +2.44 & $3 \times 10^{-21}$ & 56 \\
\hline Interferon- $a 2$ & IFNA2(A/B/C) & Cytokine, type I interferon & +3.46 & $2 \times 10^{-19}$ & 43 \\
\hline $\begin{array}{l}\text { Signal transducer and } \\
\text { activator of transcription } 1\end{array}$ & $\begin{array}{l}\text { STAT1, ISGF-3, CANDF7, } \\
\text { IMD31(A/B/C), STAT91 }\end{array}$ & $\begin{array}{l}\text { Transcription factor downstream } \\
\text { of interferon receptors }\end{array}$ & +2.48 & $2 \times 10^{-15}$ & 47 \\
\hline
\end{tabular}

Upstream regulators predicted by IPA to be activatory, ordered by lowest $p$ value

77\% in TREM2 KO pMac compared to WT. Compared with total adhesion, the $\alpha \mathrm{V} \beta 3 / 5$ inhibitor reduced adhesion to vitronectin by $56 \%$ in WT (significant), indicating that $\alpha \mathrm{V} \beta 3 / 5$ has a large contribution to vitronectin adhesion (Fig. 6f, first and second sets of bars). Interestingly, in the presence of $\alpha \mathrm{V} \beta 3 / 5$ inhibitor, there was significantly less adhesion of TREM2 KO versus WT pMac (Fig. 6f, second set of bars between genotypes). This suggests that other types of vitronectin-adhesion molecule are also reduced by TREM2 KO, e.g., uPAR. Our RNAseq data supports a significant downregulation of uPAR in both $\mathrm{R} 47 \mathrm{H}$ and TREM2 $\mathrm{KO}$ pMac, encoded by the PLAUR gene. TGF $\beta 1$ treatment of pMac for $24 \mathrm{~h}$ prior to the assay did not significantly increase total vitronectin adhesion (Fig. 6f, first and third set of bars); however, the $\alpha \mathrm{V} \beta 3 / 5$-specific adhesion appears to be increased (Fig. 6f, third set of bars between genotypes)). The $\alpha \mathrm{V} \beta 3 / 5$ inhibitor reduced adhesion of TGF $\beta 1$-treated cells by $76 \%$ in WT (significant), $85 \%$ in $\mathrm{R} 47 \mathrm{H}$ (significant), and $86 \%$ in TREM2 KO (not significant) (Fig. 6f, third and fourth sets of bars). The $\alpha \mathrm{V} \beta 3 / 5$-specific adhesion of TGF $\beta$-treated cells appears to be much higher than non-primed cells. Our interpretation of this data is that TGF $\beta 1$ treatment promotes $\alpha \mathrm{V} \beta 3$ expression and ligation with vitronectin, but is not sufficient to rescue adhesion of TREM2 mutant cells, perhaps due to defective expression of other adhesion molecules and cytoskeletal regulators that are not TGF $\beta$-sensitive.

\section{Discussion}

The primary aim of this study was to identify phenotypic defects caused by the R47H TREM2 mutation in a human microglia model in vitro. Although the TREM2 KO pMac exhibited significant defects of phagocytosis, migration, and survival, the $\mathrm{R} 47 \mathrm{H}$ mutation had too modest an effect on TREM2 activity to disturb the same broad cell functions. Identifying dysregulated genes with transcriptomics allowed us to design targeted cell assays and led to the discovery that R47H TREM2 significantly impairs adhesion to vitronectin, a small-scale phenotypic defect that could nonetheless be important. The general lack of gross phenotypic defects is curious in the context of previous literature. Human AD patients carrying the TREM2 risk variants have more dystrophic microglia, weaker interaction of microglia with amyloid plaques, increased dystrophic neurites, and larger areas of insoluble phosphorylated tau than age- and disease stage-matched $\mathrm{AD}$ patients without an $\mathrm{AD}$ risk variant $[55,56]$. The implications of this are that TREM2 AD risk variant microglia are dysfunctional, although the precise mechanistic details have not been defined. With regard to the lack of gross phenotypic defects, clearly there are three major components missing from our in vitro model compared with human AD brains-ageing, environment, and interactions with other cell types-and the pathogenic effects of the R47H TREM2 mutation may be more evident in combination with these missing components.

\section{Effect of R47H on TREM2}

We firstly validated TREM2 expression and activity in the $\mathrm{R} 47 \mathrm{H}$ TREM2 pMac and identified a reduction in cell surface expression of TREM2 and increased shedding compared with isogenic WT pMac. This finding is supported by a study of AD patients' cerebrospinal fluid, which showed that p.R47H carriers had higher sTREM2 levels than non-carriers [57]. However, another study of human $\mathrm{AD}$ brain cortices, examining detergentextracted C-terminal fragments of TREM2 as a proxy for TREM2 shedding, found no difference between p.R47H and non-carriers [58]. A potential explanation for this is that the R47H TREM2 mutation is always heterozygous when identified in human $A D$ patients, and therefore, the overall impact on TREM2 surface expression is small. We used a homozygous R47H TREM2 line to offer the maximum opportunity to detect potential phenotypic defects, without compensation from a normal allele, although this strategy has the limitation of not replicating the mutation dosage associated with the monoallelic $\mathrm{R} 47 \mathrm{H}$ mutation common in human $\mathrm{AD}$; therefore, the impact of the mutation on phenotype could be overstated in biallelic cells. Three previous studies found no abnormality of R47H TREM2 cell surface expression in cell cultures; however, these either 
overexpressed human TREM2 in HEK293 cell lines [19, 59] or used gene-edited mice that express murine TREM2 [60], which undergoes abnormal splicing when $\mathrm{R} 47 \mathrm{H}$ is inserted [25]. On the other hand, changes to TREM2 complex glycosylation, and reduced stability and retromer-mediated receptor recycling have been detected in transfected HeLa cells [61, 62]. Although most sTREM2 is produced by proteolytic cleavage of the fulllength TREM 2 protein, about $25 \%$ in human brains is estimated to originate from expression of a shorter splice isoform of TREM2 that lacks the transmembrane domain (ENST00000338469) [63, 64]. To ascertain whether the increased sTREM2 production of R47H TREM2 cells originates from a short isoform of TREM2, we performed differential transcript usage analysis on our RNA-seq dataset (Additional file 1: Fig. S10). There was no significant difference to the use of TREM2 alternative transcripts in the $\mathrm{R} 47 \mathrm{H}$ line compared with WT, which supports previous literature [63]. In the literature, there is no direct connection between $\mathrm{R} 47 \mathrm{H}$ and TREM2 shedding, but we speculate that reduced TREM2 ligand engagement could allow sheddases greater access to TREM2, whereas in the ligated state, TREM2 may be inaccessible to sheddases. One potential mechanism is that ligated TREM2-DAP12 complexes may segregate to "lipid rafts" in the plasma membrane [65, 66], whereas ADAM10 is thought to be excluded from lipid rafts [67]. Another possibility is that tight "immunological synapses" form between the iPSC-macrophage and TREM2activating target membranes, e.g., dead cells, excluding proteins with larger extracellular domains such as ADAM10. Future work to distinguish the two mechanisms could include co-localization studies of ADAM10 with TREM2 and lipid raft markers. Nevertheless, despite reduced cell surface expression of TREM2 in R47H TREM2 pMac, robust downstream signalling was provoked by a TREM2activating antibody and by dead neurons, demonstrating no significant reduction in downstream SYK and calcium signalling (Figs. $1 \mathrm{~h}$, $\mathrm{i}$ and $2 \mathrm{~h}$ ).

\section{Previous literature on effect of R47H TREM2 on microglia function}

The TREM2-dependent phenotypes that we have published with TREM2 KO pMac are in strong agreement with previous literature. iPSC-derived microglia-like cells with either TREM2 KO or severe loss-of-function mutations (T66M, W50C) have reduced phagocytosis of apoptotic neurons and amyloid plaques, and poorer survival after M-CSF withdrawal, but no significant defect in TLR4-mediated cytokine responses [11, 27, 51, 68]. Claes et al. generated the first published $\mathrm{R} 47 \mathrm{H}$ mutation in human embryonic stem cells and showed that it had no impact on phagocytosis of ex vivo amyloid plaques or E. coli by microglia-like cells, whereas TREM2 $2^{-/+}$and -l- cells had defective phagocytosis of these cargoes, agreeing with our findings that $\mathrm{R} 47 \mathrm{H}$ does not phenocopy TREM2 deficiency in human microglia models [27]. We show that the R47H mutation attenuates IFN $\gamma$ primed LPS inflammation, an observation that is also in agreement with a recent study by Piers et al. [28]. Piers et al. identified a "locked immunometabolic switch" in the same $\mathrm{R} 47 \mathrm{H}$ homozygous iPSC line used in this manuscript, namely a defect in upregulating glycolytic energy production in response to sudden energy demands placed on the cell, for example proinflammatory stimulation [28]. Cytokine secretion, phagocytosis, and migration require the cells to alter their metabolism rapidly, increasing glycolysis to supply energy. Importantly, metabolic defects in $\mathrm{R} 47 \mathrm{H}$ cells were uncovered using manipulations with LPS + IFN $\gamma$ and glycolysis inhibitors, whereas the cells were similar to the isogenic control when unstimulated [28]. This suggests that pathogenic manifestation of the mutation requires cell stress or high levels of activation. In contrast to our findings, a study of human R47H TREM2 expressed in a mouse tauopathy revealed striking attenuation of microgliosis and reduced phagocytosis of synaptic elements by microglia [69]. The authors also measured significantly lower levels of phagocytosed synapse material in microglia of human AD brains with R47H/R62H TREM2 variant, versus case-matched AD brains with TREM2 common variant. The reduction in synapse phagocytosis mirrors the effect of TREM2 KO in our data and in the literature. This provides further support to our hypothesis that in a "disease" setting, the R47H TREM2 mutation causes measurable phenotypic defects that reflect a reduction of TREM2 function. Our in vitro model recreates healthy isolated microglia, and under these conditions, the R47H TREM2 cells did not exhibit significant defects of synaptosome phagocytosis.

\section{Basis of divergent cell phenotypes of R47H TREM2 and TREM2 KO}

In the absence of overt phenotypic defects in the $\mathrm{R} 47 \mathrm{H}$ TREM2 pMac, we turned to transcriptomics to uncover any "hidden" dysfunction. Contrasting with the divergent physical phenotypes, there was high overlap between DEGs identified in R47H TREM2 pMac and TREM2 $\mathrm{KO}$. With very few dysregulated genes that are unique to the R47H TREM2 pMac, it is unlikely that these can explain the major differences in phenotype between the $\mathrm{R} 47 \mathrm{H}$ and $\mathrm{KO}$ lines. The largest discrepancy is the gene CHCHD2, which is transcriptionally upregulated 21-fold in TREM2 $\mathrm{KO}$ and downregulated 153-fold by $\mathrm{R} 47 \mathrm{H}$ TREM2 relative to the WT (Fig. 5a; Additional file 1: Fig. S8). Loss of function mutations of $\mathrm{CHCHD} 2$ are linked to autosomal dominant Parkinson's disease, and CHCHD2 encodes a protein proposed to have multiple 
roles as a mitochondrial ROS scavenger, scaffold, inhibitor of apoptosis, and transcription factor, collectively promoting activity and stability of the mitochondrial respiratory chain in response to mitochondrial stressors [70-72]. The only gene known to be directly regulated by $\mathrm{CHCHD} 2$ is COX4I2, which was not differentially expressed in TREM2 $\mathrm{KO}$ or $\mathrm{R} 47 \mathrm{H}$, so it is not clear whether $\mathrm{CHCHD} 2$ dysregulation in $\mathrm{R} 47 \mathrm{H}$ or $\mathrm{KO}$ has biological relevance in pMac. A more likely explanation for the absence of phenotypic defects in the $\mathrm{R} 47 \mathrm{H}$ line is that less than a third of the genes affected in the $\mathrm{KO}$ were significantly dysregulated, with the degree of upregulation or downregulation frequently intermediate to the $\mathrm{KO}$ (Figs. 4c and 5a). Although transcriptional dysregulation is evident in unstimulated $\mathrm{R} 47 \mathrm{H}$ pMac, there may be sufficient tonic TREM2-DAP12 activity under standard cell culture conditions to avoid overt phenotypic defects. Furthermore, there is a degree of redundancy in the regulation of important microglia functions. For example, we demonstrated that TREM2 KO only has a detrimental effect on long-term survival when M-CSF/ CSF1 is removed from the media (Fig. 3e-f). Standard cell culture conditions include excess M-CSF/CSF1, and CSF1 receptor signalling converges on similar downstream mediators to TREM2, potentially mitigating the impact of TREM2 loss of function on multiple phenotypes.

\section{Previous transcriptomic studies of TREM2 KO and R47H TREM2}

The transcriptional effects of TREM2 knockout have been previously studied in mouse models [73-77] and human stem cell-derived microglia-like cells [11, 27]. Our study is consistent with two mouse studies that demonstrated enrichment of pathways relating to inflammatory and cytokine responses, and chemotactic motility $[45,73]$. On the other hand, genes identified in mice to be "homeostatic" are highly upregulated in Trem2 KO mouse microglia relative to WT, such as P2ry12, Mertk, and Tmem119, which are not significantly altered in our human TREM2 KO pMac. A third Trem2 KO mouse study primarily found enrichment for unfolded protein response and protein ubiquitination [74]. Unfolded protein response was not significantly enriched in our TREM2 KO transcriptome, but the protein ubiquitination was enriched in PPI "group 3" for TREM2 KO. Species-specific differences may account for some discrepancy of our transcriptome with the mouse studies. Zhou et al. (2020) observed that a microglial "disease-associated" transcriptional signature in human $\mathrm{AD}$ brain was distinct from that identified in mouse AD models previously, with very few genes in common [78]. In TREM2 KO human stem-cell-derived microglia-like cells, two independent transcriptomic analyses have been performed previously in the literature $[11,27]$. Comparing significant DEGs identified by Claes et al. [27] with our own, there is significant correlation (Additional file 1: Fig. S11). Considering the distinct differentiation protocol and cell line used in Claes et al. [27], this finding is encouraging. The top GO pathways identified in the Claes et al. study are consistent with our study, with upregulation of cytokine/chemokine activity and calcium ion binding, and downregulation of extracellular matrix structure and integrins [27]. Andreone et al. [11] specifically examined dysregulated genes shared by both TREM2 KO and PLCG2 KO iPSCmicroglia-like cells, therefore a subset of TREM2 KO DEGs, and found significant enrichment for DAP12mediated signalling, phagocytosis of pathogens, and complement system in TREM2 KO. We did not find that these were highly enriched GO pathways in our whole TREM2 KO transcriptome, but noted significant upregulation of some key genes associated with these processes, including $S Y K, P L C G 2, F C G R 1 B / C, C R 1$, C3AR1, and C5AR1/2.

\section{TGF $\beta 1$ in the context of microglia function and AD}

We identified potential chemical and biologic agents that could reverse transcriptional dysregulation of the TREM2 KO (and by implication R47H TREM2). Interestingly, the immunosuppressive steroid drug, dexamethasone, was the strongest predicted upstream regulator opposing TREM2 KO (Table 2). The effects of dexamethasone on TREM2 signalling pathways will be followed up in subsequent work. In our current study, we investigated TGF $\beta 1$, the second highest hit in Table 2. TGF $\beta 1$ is a growth factor crucial for maintaining microglial "identity" of murine primary microglia after removal from the brain [79] and is used in some differentiation protocols for iPSC-microglia-like cells [42]. However, it is not supplemented in our differentiation protocol. Our iPSC-macrophages secrete TGF $\beta 1$ in culture, at similar levels to previously published rat microglia [80]. Secretion is SYK-dependent, and TREM2 KO pMac express reduced levels of TGF $\beta 1$. The assay that we used for TGF $\beta 1$ does not discriminate between inactive and active TGF $\beta 1$; therefore, further work would be needed to confirm that these differences translate to a change in TGF $\beta$ receptor activation. Supplementation of cultures with TGF $\beta 1$ for $24 \mathrm{~h}$ resulted in increased expression of the vitronectin receptor ( $\alpha \mathrm{V} \beta 3$ integrin) and appeared to promote $\alpha \mathrm{V} \beta 3$-dependent cell adhesion to vitronectin (Fig. 6e-f). Interestingly, TGF $\beta 1$ has long been linked to $\mathrm{AD}$ in the literature. There is evidence of increased TGF $\beta 1$ in cerebrospinal fluid of AD patients; however, downstream SMAD-dependent signalling of TGF $\beta$ receptors is hypothesised to be dysfunctional in $\mathrm{AD}$ [81]. In mouse $\mathrm{AD}$ models, stimulating TGF $\beta 1$ levels by 
various pharmacological means is neuroprotective and may be partly mediated by a reduction in microglial inflammation and increased degradation of $\mathrm{A} \beta$ by microglia [81]. We aimed to validate a bioinformatic prediction, rather than demonstrate the therapeutic usefulness of TGF $\beta 1$, which has been done by others (e.g., references $[82,83])$. TGF $\beta 1$ promoted vitronectin receptor expression as predicted; however, this did not fully rescue the defective vitronectin adhesion of $\mathrm{R} 47 \mathrm{H}$ TREM2 and TREM2 KO pMac. We speculate that vitronectin adhesion requires additional surface molecules such as uPAR that may be downregulated in $\mathrm{R} 47 \mathrm{H}$ and TREM2 KO pMac.

\section{Conclusions}

In a model of human microglia, we show that the $\mathrm{R} 47 \mathrm{H}$ TREM2 risk variant for AD has similar transcriptional dysregulation to TREM2 KO, but does not share deficits of phagocytosis, chemotaxis, and survival that manifest in the TREM2 KO cells. Transcriptomics shone a light on specific defects in adhesion that are shared by $\mathrm{R} 47 \mathrm{H}$ TREM2 and TREM2 KO cells. We additionally predicted that TGF $\beta 1$ may alleviate some deficits caused by the TREM2 KO; however, the effect of TGF $\beta 1$ on cell adhesion was limited. Given that the R47H mutation leads to a 2- to 4.5-fold increased risk of $\mathrm{AD}[18,20]$, it is worth using the transcriptomic information to continue to identify microglial phenotypes affected by the risk allele, and potential therapeutic targets.

\section{Supplementary information}

Supplementary information accompanies this paper at https://doi.org/10. 1186/s13195-020-00709-z.

Additional file 1 : Figure S1. Validation of R47H genotype. (A) CRISPR single guide RNA used for insertion of R47H mutation by Bioneer. (B) Chromatograms from sequencing of $\mathrm{WT}$ line BIONi010-C and $\mathrm{R} 47 \mathrm{H}$ TREM2 line BIONi010-C-7. Red asterisk indicates the R47H mutation, black asterisks are silent mutations added by Bioneer to prevent re-cutting. Figure S2. SNP microarray of iPSCs. Chromosome karyograms from Illumina microarray SNP analysis, showing (A) BIONi010-C line, (B) BIONi010-C-7 R47H TREM2 line, (C) BIONi010-C-17 TREM2 KO line. Figure S3. Validation of R47H TREM2 and TREM2 KO pMac. (A) Macrophage surface markers CD11b, CD14, and CD45 measured by flow cytometry. Median fluorescence intensity (MFI) for each sample was normalized to the relevant isotype IgG, and then to the average for the three genotypes. Histogram shows means \pm SEM, for $n=3-4$ harvests. 1-way ANOVA with Dunnett's post-hoc test, comparisons to WT line. ${ }^{* *} p<0.01$, ${ }^{* * *} p<0.001$, **** $p<$ 0.0001 , all unannotated comparisons are not significant. (B) Total levels of TREM2 protein shown in a representative western blot (WB). (C-D) Surface TREM2 measured by immunofluorescence staining (IF): live pMac were stained with TREM2 antibody, followed by fluorescent secondary antibody, and subsequently fixed. Images are maximum projections from a zstack of 5 slices, 1-5 $\mu \mathrm{m}$, taken on an Opera Phenix microscope (Perkin Elmer). Quantified mean fluorescence (per $\mu m^{2}$ ), for triplicate wells, was normalised to the average for the three genotypes, and then expressed as a ratio of whole-cell TREM2 staining from separate permeabilised wells on the same plate (D). Means \pm SEM, for $N=3$ harvests, $p=0.047$ in onetailed paired t-test. (E-F) Kinetics of pMac calcium responses to $0.5 \mathrm{mM}$ $\operatorname{ATP}(E)$, and $10 \mu \mathrm{g} / \mathrm{mL}$ TREM2 antibody (F). Means \pm SEM, for $N=3-5$ harvests. Figure S4. Validation of antibodies for TREM2 immunocytochemistry. Fixed and permeabilized WT, R47H, and TREM2 KO pMac were stained for 1 hour at RT with three different TREM2 antibodies at the concentrations indicated, followed by staining with Alexa Fluor 488conjugated secondary antibody (1:1000, Invitrogen). Cells were counterstained with DAPI nuclear dye and imaged on an EVOS FL Auto automated microscope (Thermo Fisher). Ab209814 showed cytoplasmic staining in all three genotypes, 13,483-1-AP showed nuclear staining in all three genotypes, whereas AF1828 stained cytoplasm and plasma membrane in WT and R47H TREM2 pMac but not TREM2 KO pMac. Scale bar is $100 \mu \mathrm{m}$. Figure S5. Validation of dead SH-SY5Y phagocytosis assay. (A) Freshly-fixed SH-SY5Ys stain uniformly for phosphatidylserine exposure (annexin V-FITC), but have limited cell permeability (propidium iodide). Live SH-SY5YS do not stain for annexin V-FITC or propidium iodide, except for focal staining present on the few dead cells in culture. (B) No TREM2 expression in an SH-SY5Y not undergoing phagocytosis, marked with a white arrow. (C) No RAB9 expression in non-engulfed SH-SY5Y, marked with a white arrow. (D) Dose-dependent uptake of dead SHSY5YS after 5 hours of phagocytosis with WT line BIONi010-C, means quantified from three independent experiments for $\%$ of spot positive (phagocytic) cells per well. Means \pm SEM, for $N=3$ harvests. (E) Phagocytosis of 3 hours is inhibited with $10 \mu \mathrm{M}$ cytochalasin D, $1 \mu \mathrm{M}$ bafilomycin A1, $1 \mu \mathrm{M}$ jasplakinolide, all with 1 hour pre-treatment, and $13 \mu \mathrm{g} / \mathrm{mL}$ recombinant annexin $V$ added simultaneously to the dead SH-SY5Ys. Data was normalized to mean for each genotype per experiment. Means \pm SEM, for N=3-6 harvests and with two WT cell lines (SFC840-03-03, the characterisation of this line is described in Fernandes et al [32], and BIONi010-C). 1-way ANOVA with Dunnett's post-hoc test, comparisons to untreated cells. ${ }^{*} p<0.05,{ }^{* * *} p<0.001$. Figure $\mathbf{S 6}$. Validation of synaptosome phagocytosis assay. (A) Two whole synaptosomes surrounded by cell debris in the cryopreserved prep, visualised by negative staining electron microscopy. White asterisks label the pre-synaptic termini, with many pre-synaptic vesicles, whereas purple asterisks label the post-synaptic termini. A dark post-synaptic density can be seen between connected preand post-synaptic termini. (B) Synaptosomes stain uniformly for phosphatidylserine exposure (annexin V-FITC), comparison is with unstained synaptosomes. An area magnified by $5 X$ is shown inset. (C) Dose-dependent uptake of dead SH-SY5Ys after 3 hours of phagocytosis with WT line BIONi010-C, reaching saturation above $30 \mu \mathrm{g}$. (D) Phagocytosis in BIONi010-C pMac is inhibited by $10 \mu \mathrm{M}$ cytochalasin D and $1 \mu \mathrm{M}$ bafilomycin A1, and increased by prior opsonisation of synaptosomes for 30 minutes with $20 \%$ human serum. Data was normalized to mean for each genotype per experiment, and is represented as sum of spot areas $\left(\mu \mathrm{m}^{2}\right)$ per cell. Means \pm SEM, for $N=3-4$ harvests. 1-way ANOVA with Dunnett's post-hoc test, comparisons to untreated cells. ${ }^{*} p<0.05$, ${ }^{* *} p<0.01$. Figure S7. Validation for cytokine ELISAs and transwell chemotaxis assay. Cytokine ELISAs: (A) Secretion of TNF in response to 4 hours of 0.1-1 $\mu \mathrm{g}$ / $\mathrm{mL}$ LPS. (B) Secretion of IL-6 in the same supernatants as (A). Means \pm SEM, for $\mathrm{N}=3$ harvests. 2-way ANOVA with Dunnett's post-hoc test. Comparisons with the coloured annotations are stimulations versus untreated cells (None) for each genotype. Comparisons with the black annotations are $\mathrm{R} 47 \mathrm{H}$ or $\mathrm{KO}$ versus the WT line for each stimulation, all unannotated comparisons are not significant. Transwell chemotaxis assay: (C) Migration of WT pMac in transwell chemotaxis assay in the presence of four concentrations of ADP or C5a, for 6 hours. (D) Migration of WT pMac for 6 hours in the presence of $30 \mu \mathrm{M}$ ADP is attenuated by 30 minutes pretreatment with a P2RY12-selective inhibitor (PSB0739), but not a P2RY1 (MRS2179) or P2RY13 (MRS2211) inhibitor. (E) Migration of WT pMac for 6 hours in the presence of $3 \mathrm{nM} \mathrm{C} 5 \mathrm{a}$ is attenuated by 30 minutes pretreatment with a C5aR inhibitor (PMX-53), or a Syk inhibitor (OXSI-2, 3 $\mu M)$. Means $\pm S E M$, for $N=3-4$ harvests. 1-way ANOVA with Dunnett's post-hoc test, pairwise comparisons to control. ${ }^{*} p<0.05$, ${ }^{* *} p<0.01$, *** $p<0.001,{ }^{* * *} p<0.0001$. Figure S8. RNA-seq differentially-expressed genes (DEGs). Volcano plots shown for DEGs relative to WT: (A) TREM2 $\mathrm{KO}$ and (B) R47H TREM2 pMac. Dashed lines show cut-offs at log2-foldchange $=2$ and $p=0.001$. Enrichment of Gene Ontology (GO) terms in significant (adjusted $p$ value $<0.05$ ) DEGs relative to WT: (C) TREM2 KO, and (D) R47H TREM2 pMac. Top 30 terms shown in order of the adjusted $p$ value, the relative $\mathrm{R}$-score represents the average direction of change. Circle size corresponds with number of DEGs. Figure S9. Flow cytometry 
of integrins. Representative flow cytometry histograms for Figure 6e. Figure S10. Proportions of TREM2 transcript splice variants. TREM2 differential transcript usage analysis was performed on the RNA-seq data with the DRIMSeq bioconductor package, using Salmon-quantified transcript counts. DRIMSeq assumes an Dirichlet Multinomial model (DM) for each gene, where the total count for the gene is considered fixed, and the quantity of interest is the proportion for the transcript within a gene for each sample. A likelihood ratio test was used to test for gene and transcript level DTU between R47H vs WT, and no significant difference in transcript usage was found. Transcripts are described in Del-Aguila et al [62]: ENST00000373113 is the canonical TREM2 transcript and the longest, with five exons; ENST00000373122 is the second longest and lacks the 5' exon but includes the transmembrane domain; ENST00000338469 is the shortest and excludes the transmembrane domain. The bars represent three sequential ages of iPSC-macrophages. Figure S11. Correlation of TREM2 KO DEGs with Claes et al (2019). Log-2-fold change values for the significant DEGs (adjusted $p$ value $<0.05$ ) of the current study (purple) plotted against significant DEGs from Claes et al (orange). Overlapping significant DEGs shown in green.

Additional file 2. : Video 1. Time-lapse video of dead SH-SY5Y phagocytosis assay. WT pMac phagocytosing pHrodo-labelled fixed SH-SY5Ys, displaying an increase in red fluorescence of the SH-SY5Ys after engulfment. In 96wp, $2 \times 10^{4} \mathrm{pMac}$ were given $2 \times 10^{4} \mathrm{SH}-\mathrm{SY} 5 \mathrm{Ys}$, and images taken every 10 minutes at 20x for 3 hours, using an EVOS FL Auto automated microscope. Video is 2 frames per second.

Additional file 3. : Video 2. Time-lapse video of synaptosome phagocytosis assay. WT pMac phagocytosing pHrodo-labelled synaptosomes, displaying an increase in red fluorescence of the synaptosomes after engulfment. In 96wp, $2 \times 10^{4} \mathrm{pMac}$ were given $1 \mu \mathrm{g}$ of synaptosomes, and images taken every 10 minutes at 20x for 3 hours, using an EVOS FL Auto automated microscope. Video is 2 frames per second.

Additional file 4 Results of RNA-seq differential gene expression analysis with DESeq2. DESeq2 output for R47H TREM2 vs WT and TREM2 KO vs WT, with gene name, relative expression ("Base Mean"), log-2-fold-change from the WT, and Benjamini-Hochberg-adjusted $p$ values indicated.

Additional file 5. Results of RNA-seq Ingenuity Pathways Analysis on TREM2 KO PPI groups. For each PPI group separate files give information about the genes assigned to that group (suffix " Genes"), the predicted upstream regulators with Activation Z-score indicating whether the change mimics (+) or opposes (-) TREM2 KO transcriptional effects (suffix "_UpstreamAnalysis"), and the relationship of predicted upstream regulators to disease/functions (suffix "_RegulatorEffects").

\section{Abbreviations}

KO: Knockout; iPSC: Induced pluripotent stem cell; pMac: iPSC-macrophage; LPS: Lipopolysaccharide; PtdSer: Phosphatidylserine; RT: Room temperature

\section{Acknowledgements}

The authors thank Dr. Val Millar and Dr. Sohaib Nizami for their assistance with high-content microscopy, and Dr. Daniel Ebner for access to the highcontent microscopes. Rats for the synaptosomes were obtained with assistance by Ms. Debbie Cobley. Assistance with rat dissections was given by Ms. Milena Cioroch and Dr. Natalie Connor-Robson, with kind thanks, and rat synaptosome purification was performed with aid from Dr. Sohaib Nizami. Electron microscopy was performed by the Sir William Dunn School Electron Microscopy Facility, with thanks to Dr. Errin Johnson and Ms. Raman Dhaliwal. We thank the Oxford Genomics Centre at the Wellcome Centre for Human Genetics (funded by Wellcome Trust grant reference 203141/Z/16/Z) for the generation and initial processing of sequencing data.

\section{Authors' contributions}

S.A.C., E.D., and J.B.D. conceived the study and designed the project; H.H-R. performed most of the experiments and analysis of the data and wrote the manuscript; D.A. analysed and produced figures for the RNA-seq data; J.O. performed the calcium assays and IL-6 ELISAs and analysed that data; T.B.S. performed and analysed the sTREM2 ELISA; J.M-S. ran Integrated Pathway Analysis on the RNA-seq data; C.W. gave advice on the analysis of the RNAseq data; E.M. and W.S.J. gave scientific input and advice and proof-read the manuscript. All authors read and approved the final manuscript.

\section{Funding}

This work was supported by the Alzheimer's Research UK Oxford Drug Discovery Institute (ARUK ODDI, grant reference ARUK-2020DDI-OX), with additional support to the James Martin Stem Cell Facility Oxford (S.A.C.) from the Oxford Martin School LC0910-004; Monument Trust Discovery Award from Parkinson's UK (J-1403); the MRC Dementias Platform UK Stem Cell Network Capital Equipment MC_EX_MR/N50192X/1, Partnership MR/N013255/1, and Momentum MC_PC_16034 Awards. Generation of Illumina genotyping data was performed by the High-Throughput Genomics Group at the Wellcome Trust Centre for Human Genetics, Oxford (funded by Wellcome Trust grant reference 090532/Z/09/Z and MRC Hub grant G0900747 91070). Generation of RNA sequencing data was performed by the Oxford Genomics Centre at the Wellcome Centre for Human Genetics (funded by Wellcome Trust grant reference 203141/Z/16/Z).

\section{Availability of data and materials}

Data generated or analysed during this study are included in this published article and its supplementary information files, apart from the RNA-seq dataset, which is deposited in NCBI's Gene Expression Omnibus (Edgar et al., 2002) and is accessible through GEO Series accession number GSE157635 (https://www.ncbi.nlm.nih.gov/geo/query/acc.cgi?acc=GSE157635)..

\section{Ethics approval and consent to participate}

The WT parent line BIONi010-C was generated by Bioneer from normal adult human skin fibroblasts sourced from Lonza (\#CC-2511), who provide the following ethics statement: 'These cells were isolated from donated human tissue after obtaining permission for their use in research applications by informed consent or legal authorization.' For Fig. S5 (Additional file 1), pMac differentiated from SFC840-03-03 iPSC were used. SFC840-03-03 was derived from dermal fibroblasts from a disease-free donor recruited through the Oxford Parkinson's Disease Centre, having given signed informed consent, which included derivation of hiPSC lines from skin biopsies (Ethics Committee: National Health Service, Health Research Authority, NRES Committee South Central, Berkshire, UK (REC 10/H0505/71)).

\section{Consent for publication}

Not applicable.

\section{Competing interests}

The authors declare that they have no competing interests.

\section{Author details}

1James Martin Stem Cell Facility, Sir William Dunn School of Pathology, University of Oxford, Oxford OX1 3RE, UK. ${ }^{2}$ Nuffield Department of Medicine Research Building, Alzheimer's Research UK Oxford Drug Discovery Institute, University of Oxford, Oxford OX3 7FZ, UK. ${ }^{3}$ Weatherall Institute of Molecular Medicine, University of Oxford, Oxford OX3 9DS, UK. ${ }^{4}$ UK Dementia Research Institute, Cardiff University, Cardiff CF24 4HQ, UK.

\section{Received: 28 February 2020 Accepted: 20 October 2020}

Published online: 16 November 2020

\section{References}

1. Sims R, van der Lee SJ, Naj AC, Bellenguez C, Badarinarayan N, Jakobsdottir J, et al. Rare coding variants in PLCG2, ABI3, and TREM2 implicate microglial-mediated innate immunity in Alzheimer's disease. Nat Genet. 2017:49(9):1373-84.

2. Nizami S, Hall-Roberts H, Warrier S, Cowley SA, Di Daniel E. Microglial inflammation and phagocytosis in Alzheimer's disease: potential therapeutic targets. Br J Pharmacol. 2019;176(18):3515-32.

3. Nott A, Holtman IR, Coufal NG, Schlachetzki JCM, Yu M, Hu R, et al. Brain cell type-specific enhancer-promoter interactome maps and disease risk association. Science. 2019;366(6469):1134-9.

4. Song WM, Colonna M. The identity and function of microglia in neurodegeneration. Nat Immunol. 2018;19(10):1048-58.

5. Kober DL, Brett TJ. TREM2-ligand interactions in health and disease. J Mol Biol. 2017:429(11):1607-29.

6. Takahashi K, Rochford CDP, Neumann H. Clearance of apoptotic neurons without inflammation by microglial triggering receptor expressed on myeloid cells-2. J Exp Med. 2005;201(4):647-57. 
7. Koth $L L$, Cambier CJ, Ellwanger A, Solon M, Hou L, Lanier LL, et al. DAP12 is required for macrophage recruitment to the lung in response to cigarette smoke and chemotaxis toward CCL2. J Immunol. 2010;184(11):6522-8.

8. Wang Y, Ulland TK, Ulrich JD, Song W, Tzaferis JA, Hole JT, et al. TREM2mediated early microglial response limits diffusion and toxicity of amyloid plaques. J Exp Med. 2016;213(5):667-75.

9. Otero K, Shinohara M, Zhao H, Cella M, Gilfillan S, Colucci A, et al. TREM2 and $\beta$-catenin regulate bone homeostasis by controlling the rate of osteoclastogenesis. J Immunol. 2012;188(6):2612-21.

10. Ulland TK, Song WM, Huang SCC, Ulrich JD, Sergushichev A, Beatty WL, et al. TREM2 maintains microglial metabolic fitness in Alzheimer's disease. Cell. 2017;170(4):649-663.e13.

11. Andreone BJ, Przybyla L, Llapashtica C, Rana A, Davis SS, van Lengerich B, et al. Alzheimer's-associated PLCY2 is a signaling node required for both TREM2 function and the inflammatory response in human microglia. Nat Neurosci. 2020; https://doi.org/10.1038/s41593-020-0650-6.

12. Bouchon A, Hernández-Munain C, Cella M, Colonna M. A DAP12-mediated pathway regulates expression of CC chemokine receptor 7 and maturation of human dendritic cells. J Exp Med. 2001;194(8):1111-22.

13. Wang Y, Cella M, Mallinson K, Ulrich JD, Young KL, Robinette ML, et al. TREM2 lipid sensing sustains the microglial response in an Alzheimer's disease model. Cell. 2015;160(6):1061-71.

14. Yeh FL, Wang Y, Tom I, Gonzalez LC, Sheng M. TREM2 binds to apolipoproteins, including APOE and CLU/APOJ, and thereby facilitates uptake of amyloid-beta by microglia. Neuron. 2016;91(2):328-40.

15. N'Diaye EN, Branda CS, Branda SS, Nevarez L, Colonna M, Lowell C, et al. TREM-2 (triggering receptor expressed on myeloid cells 2 ) is a phagocytic receptor for bacteria. J Cell Biol. 2009;184(2):215-23.

16. Kawabori M, Kacimi R, Kauppinen T, Calosing C, Kim JY, Hsieh CL, et al. Triggering Receptor Expressed on Myeloid Cells 2 (TREM2) deficiency attenuates phagocytic activities of microglia and exacerbates ischemic damage in experimental stroke. J Neurosci. 2015;35(8):3384 LP-3396.

17. Zhong L, Wang Z, Wang D, Wang Z, Martens YA, Wu L, et al. Amyloid-beta modulates microglial responses by binding to the triggering receptor expressed on myeloid cells 2 (TREM2). Mol Neurodegener. 2018;13(1):1-12.

18. Guerreiro R, Ph D, Wojtas A, Bras J, Carrasquillo M, Rogaeva E, et al. TREM2 variants in AD. N Engl J Med. 2013;368(2):117-27.

19. Kleinberger G, Yamanishi $Y$, Suárez-Calvet M, Czirr E, Lohmann E, Cuyvers E, et al. TREM2 mutations implicated in neurodegeneration impair cell surface transport and phagocytosis. Sci Transl Med. 2014;6(243):243ra86.

20. Jonsson T, Stefansson H, Steinberg S, Jonsdottir I, Jonsson P, Snaedal J, et al Variant of TREM2 associated with the risk of AD. N Engl J Med. 2013;368(2): 107-16.

21. Bailey CC, Devaux LB, Farzan M. The triggering receptor expressed on myeloid cells 2 binds apolipoprotein E. J Biol Chem. 2015;290(43):26033-42.

22. Sudom A, Talreja S, Danao J, Bragg E, Kegel R, Min X, et al. Molecular basis for the loss-of-function effects of the Alzheimer's disease-associated R47H variant of the immune receptor TREM2. J Biol Chem. 2018;293(32):12634-46.

23. Shirotani K, Hori Y, Yoshizaki R, Higuchi E, Colonna M, Saito T, et al. Aminophospholipids are signal-transducing TREM2 ligands on apoptotic cells. Sci Rep. 2019;9(1):1-9.

24. Cheng-Hathaway PJ, Reed-Geaghan EG, Jay TR, Casali BT, Bemiller SM, Puntambekar SS, et al. The Trem2 R47H variant confers loss-of-function-like phenotypes in Alzheimer's disease. Mol Neurodegener. 2018;13(1):1-12.

25. Xiang X, Piers TM, Wefers B, Zhu K, Mallach A, Brunner B, et al. The Trem2 $\mathrm{R} 47 \mathrm{H}$ Alzheimer's risk variant impairs splicing and reduces Trem2 mRNA and protein in mice but not in humans. Mol Neurodegener. 2018;13(1):49.

26. Song WM, Joshita S, Zhou Y, Ulland TK, Gilfillan S, Colonna M. Humanized TREM2 mice reveal microglia-intrinsic and -extrinsic effects of $\mathrm{R} 47 \mathrm{H}$ polymorphism. J Exp Med. 2018;215(3):745-60.

27. Claes C, Van Den Daele J, Boon R, Schouteden S, Colombo A, Monasor LS, et al. Human stem cell-derived monocytes and microglia-like cells reveal impaired amyloid plaque clearance upon heterozygous or homozygous loss of TREM2. Alzheimers Dement. 2019;15(3):453-64.

28. Piers TM, Cosker K, Mallach A, Johnson GT, Guerreiro R, Hardy J, et al. A locked immunometabolic switch underlies TREM2 R47H loss of function in human iPSC-derived microglia. FASEB J. 2019;doi:https://doi.org/10.1096/fj. 201902447R.

29. van Wilgenburg B, Browne C, Vowles J, Cowley SA. Efficient, long term production of monocyte-derived macrophages from human pluripotent stem cells under partly-defined and fully-defined conditions. Plos One. 2013; 8(8):e71098.

30. Haenseler W, Sansom SN, Buchrieser J, Newey SE, Moore CS, Nicholls FJ, et al. A highly efficient human pluripotent stem cell microglia model displays a neuronal-co-culture-specific expression profile and inflammatory response. Stem Cell Rep. 2017:8(6):1727-42.

31. Buchrieser J, James W, Moore MD. Human induced pluripotent stem cellderived macrophages share ontogeny with MYB-independent tissueresident macrophages. Stem Cell Rep. 2017;8(2):334-45.

32. Fernandes HJR, Hartfield EM, Christian HC, Emmanoulidou E, Zheng Y, Booth $\mathrm{H}$, et al. ER stress and autophagic perturbations lead to elevated extracellular a-Synuclein in GBA-N370S Parkinson's iPSC-derived dopamine neurons. Stem Cell Reports. 2016;6(3):342-56.

33. Kamentsky L, Jones TR, Fraser A, Bray MA, Logan DJ, Madden KL, et al. Improved structure, function and compatibility for cellprofiler: modular highthroughput image analysis software. Bioinformatics. 2011;27(8):1179-80.

34. Dunkley PR, Jarvie PE, Robinson PJ. A rapid Percoll gradient procedure for preparation of synaptosomes. Nat Protoc. 2008;3(11):1718-28.

35. Chatr-aryamontri A, Oughtred R, Boucher L, Rust J, Chang C, Kolas NK, et al. The BioGRID interaction database: 2017 update. Nucleic Acids Res. 2016; 45(D1):D369-79.

36. López Y, Nakai K, Patil A. HitPredict version 4: comprehensive reliability scoring of physical protein-protein interactions from more than 100 species. Database (Oxford). 2015;2015:bav117.

37. Orchard S, Ammari M, Aranda B, Breuza L, Briganti L, Broackes-Carter F, et al. The MlntAct project-IntAct as a common curation platform for 11 molecular interaction databases. Nucleic Acids Res. 2013;42(D1):D358-63.

38. Szklarczyk D, Franceschini A, Wyder S, Forslund K, Heller D, Huerta-Cepas J, et al. STRING v10: protein-protein interaction networks, integrated over the tree of life. Nucleic Acids Res. 2014;43(D1):D447-52.

39. Ruepp A, Waegele B, Lechner M, Brauner B, Dunger-Kaltenbach I, Fobo G, et al. CORUM: the comprehensive resource of mammalian protein complexes_2009. Nucleic Acids Res. 2009;38(suppl_1):D497-501.

40. Fabregat A, Sidiropoulos K, Garapati P, Gillespie M, Hausmann K, Haw R, et al. The Reactome pathway knowledgebase. Nucleic Acids Res. 2015; 44(D1):D481-7.

41. Csardi G, Nepusz T. The igraph software package for complex network research. InterJ Complex Syst. 2006;1695(5):1-9.

42. Abud EM, Ramirez RN, Martinez ES, Healy LM, Cecilia HH, Newman SA, et al. iPSC-derived human microglia-like cells to study neurological diseases. Neuron. 2017;94(2):278-93.

43. Krämer A, Green J, Pollard J Jr, Tugendreich S. Causal analysis approaches in ingenuity pathway analysis. Bioinformatics. 2013;30(4):523-30.

44. Wunderlich P, Glebov K, Kemmerling N, Tien NT, Neumann H, Walter J. Sequential proteolytic processing of the triggering receptor expressed on myeloid cells-2 (TREM2) protein by ectodomain shedding and $\gamma$-secretasedependent intramembranous cleavage. J Biol Chem. 2013;288(46):33027-36.

45. Mazaheri F, Snaidero N, Kleinberger G, Madore C, Daria A, Werner G, et al. TREM2 deficiency impairs chemotaxis and microglial responses to neuronal injury. EMBO Rep. 2017;18(7):1186-98.

46. Honda S, Sasaki Y, Ohsawa K, Imai Y, Nakamura Y, Inoue $K$, et al. Extracellular ATP or ADP induce chemotaxis of cultured microglia through Gi/o-coupled P2Y receptors. J Neurosci. 2001;21(6):1975-82.

47. Isfort K, Ebert F, Bornhorst J, Sargin S, Kardakaris R, Pasparakis M, et al. Realtime imaging reveals that $P 2 Y 2$ and $P 2 Y 12$ receptor agonists are not chemoattractants and macrophage chemotaxis to complement C5a is phosphatidylinositol 3-kinase (PI3K)- and p38 mitogen-activated protein kinase (MAPK)-independent. J Biol Chem. 2011;286(52):44776-87.

48. Zheng H, Jia L, Liu CC, Rong Z, Zhong L, Yang L, et al. TREM2 promotes microglial survival by activating wnt/ $\beta$-catenin pathway. J Neurosci. 2017; 37(7):1772-84

49. Ito $H$, Hamerman JA. TREM-2, triggering receptor expressed on myeloid cell2, negatively regulates TLR responses in dendritic cells. Eur J Immunol. 2012; 42(1):176-85

50. Turnbull IR, Gilfillan S, Cella M, Aoshi T, Miller M, Piccio L, et al. Cutting edge: TREM-2 attenuates macrophage activation. J Immunol. 2006;177(6):3520-4.

51. Garcia-Reitboeck P, Phillips A, Piers TM, Villegas-Llerena C, Butler M, Mallach A, et al. Human induced pluripotent stem cell-derived microglia-like cells harboring TREM2 missense mutations show specific deficits in phagocytosis. Cell Rep. 2018;24(9):2300-11. 
52. Bohlen CJ, Bennett FC, Tucker AF, Collins HY, Mulinyawe SB, Barres BA. Diverse requirements for microglial survival, specification, and function revealed by defined-medium cultures. Neuron. 2017;94(4):759-73.

53. Welser-Alves JV, Boroujerdi A, Tigges U, Milner R. Microglia use multiple mechanisms to mediate interactions with vitronectin; non-essential roles for the highly-expressed $a v \beta 3$ and avß5 integrins. J Neuroinflammation. 2011;8: $1-10$.

54. Ferraris GMS, Schulte C, Buttiglione V, De Lorenzi V, Piontini A, Galluzzi M, et al. The interaction between UPAR and vitronectin triggers ligandindependent adhesion signalling by integrins. EMBO J. 2014;33(21):2458-72.

55. Prokop S, Miller KR, Labra SR, Pitkin RM, Hoxha K, Narasimhan S, et al. Impact of TREM2 risk variants on brain region-specific immune activation and plaque microenvironment in Alzheimer's disease patient brain samples. Acta Neuropathol. 2019;138(4):613-30.

56. Yuan $\mathrm{P}$, Condello C, Keene CD, Wang Y, Bird TD, Paul SM, et al. TREM2 haplodeficiency in mice and humans impairs the microglia barrier function leading to decreased amyloid compaction and severe axonal dystrophy. Neuron. 2016;90(4):724-39.

57. Piccio L, Deming Y, Del-Águila JL, Ghezzi L, Holtzman DM, Fagan AM, et al. Cerebrospinal fluid soluble TREM2 is higher in Alzheimer disease and associated with mutation status. Acta Neuropathol. 2016;131(6):925-33. Available from: https://pubmed.ncbi.nlm.nih.gov/26754641/. [cited 2020 Oct 13].

58. Ma L, Allen M, Sakae N, Ertekin-Taner N, Graff-Radford NR, Dickson DW, et al. Expression and processing analyses of wild type and p.R47H TREM2 variant in Alzheimer's disease brains. Mol Neurodegener. 2016;11(1):1-9.

59. Sirkis DW, Bonham LW, Aparicio RE, Geier EG, Ramos EM, Wang Q, et al. Rare TREM2 variants associated with Alzheimer's disease display reduced cell surface expression. Acta Neuropathol Commun. 2016;4(1):98.

60. Cheng Q, Danao J, Talreja S, Wen P, Yin J, Sun N, et al. TREM2-activating antibodies abrogate the negative pleiotropic effects of the Alzheimer's disease variant Trem2 R47H on murine myeloid cell function. J Biol Chem. 2018;293(32):12620-33.

61. Yin J, Liu X, He Q, Zhou L, Yuan Z, Zhao S. Vps35-dependent recycling of Trem2 regulates microglial function. Traffic. 2016;17(12):1286-96.

62. Park JS, Ji IJ, Kim DH, An HJ, Yoon SY. The Alzheimer's disease-associated R47H variant of TREM2 has an altered glycosylation pattern and protein stability. Front Neurosci. 2017;10:618.

63. Del-Aguila JL, Benitez BA, Li Z, Dube U, Mihindukulasuriya KA, Budde JP et al. TREM2 brain transcript-specific studies in AD and TREM2 mutation carriers. Mol Neurodegener. 2019;14(1):1-13.

64. Jin SC, Benitez BA, Karch CM, Cooper B, Skorupa T, Carrell D, et al. Coding variants in TREM2 increase risk for Alzheimer's disease. Hum Mol Genet. 2014;23(21):5838-46. https://doi.org/10.1093/hmg/ddu277.

65. Dong R, Tan Y, Fan A, Liao Z, Liu H, Wei P. Molecular dynamics of the recruitment of immunoreceptor signaling module DAP12 homodimer to lipid raft boundary regulated by PIP2. J Phys Chem B. 2020;124(3):504-10.

66. Deming Y, Filipello F, Cignarella F, Cantoni C, Hsu S, Mikesell R, et al. The MS4A gene cluster is a key modulator of soluble TREM2 and Alzheimer's disease risk. Sci Transl Med. 2019:11(505):eaau2291.

67. Murai T, Maruyama Y, Mio K, Nishiyama H, Suga M, Sato C. Low cholesterol triggers membrane microdomain-dependent CD44 shedding and suppresses tumor cell migration. J Biol Chem. 2011;286(3):1999-2007.

68. Brownjohn PW, Smith J, Solanki R, Lohmann E, Houlden H, Hardy J, et al. Functional studies of missense TREM2 mutations in human stem cellderived microglia. Stem Cell Rep. 2018;10(4):1294-307.

69. Gratuze M, Leyns CEG, Sauerbeck AD, St-Pierre MK, Xiong M, Kim N, et al. Impact of TREM2R47Hvariant on tau pathology-induced gliosis and neurodegeneration. J Clin Invest. 2020;130(9):4954-68. https://doi.org/10. 1172/JCl138179. [cited 2020 Oct 15].

70. Liu Y, Zhang Y. CHCHD2 connects mitochondrial metabolism to apoptosis. Mol Cell Oncol. 2015;2(4):3-5.

71. Funayama M, Ohe K, Amo T, Furuya N, Yamaguchi J, Saiki S, et al. CHCHD2 mutations in autosomal dominant late-onset Parkinson's disease: a genomewide linkage and sequencing study. Lancet Neurol. 2015;14(3):274-82.

72. Meng H, Yamashita C, Shiba-Fukushima K, Inoshita T, Funayama M, Sato S, et al. Loss of Parkinson's disease-associated protein CHCHD2 affects mitochondrial crista structure and destabilizes cytochrome c. Nat Commun. 2017:8:1-18.

73. Kang SS, Kurti A, Baker KE, Liu CC, Colonna M, Ulrich JD, et al. Behavioral and transcriptomic analysis of Trem2-null mice: not all knockout mice are created equal. Hum Mol Genet. 2018;27(2):211-23.
74. Carbajosa G, Malki K, Lawless N, Wang H, Ryder JW, Wozniak E, et al. Loss of Trem2 in microglia leads to widespread disruption of cell coexpression networks in mouse brain. Neurobiol Aging. 2018;69:151-66

75. Keren-Shaul H, Spinrad A, Weiner A, Matcovitch-Natan O, Dvir-Szternfeld R, Ulland TK, et al. A unique microglia type associated with restricting development of Alzheimer's Disease. Cell. 2017;169(7):1276-1290.e17.

76. Krasemann S, Madore C, Cialic R, Baufeld C, Calcagno N, El Fatimy R, et al. The TREM2-APOE pathway drives the transcriptional phenotype of dysfunctional microglia in neurodegenerative diseases. Immunity. 2017; 47(3):566-581.e9.

77. Nugent AA, Lin K, van Lengerich B, Lianoglou S, Przybyla L, Davis SS, et al. TREM2 regulates microglial cholesterol metabolism upon chronic phagocytic challenge. Neuron. 2020;105(5):837-854.e9.

78. Zhou Y, Song WM, Andhey PS, Swain A, Levy T, Miller KR, et al. Human and mouse single-nucleus transcriptomics reveal TREM2-dependent and TREM2independent cellular responses in Alzheimer's disease. Nat Med. 2020;26(1): 131-42.

79. Butovsky O, Jedrychowski MP, Moore CS, Cialic R, Lanser AJ, Gabriely G, et al. Identification of a unique TGF- $\beta$-dependent molecular and functional signature in microglia. Nat Neurosci. 2014;17(1):131-43.

80. Islam A, Choudhury ME, Kigami Y, Utsunomiya R, Matsumoto S, Watanabe $\mathrm{H}$, et al. Sustained anti-inflammatory effects of TGF- $\beta 1$ on microglia/ macrophages. Biochim Biophys Acta Mol Basis Dis. 2018;1864(3):721-34.

81. Caraci F, Battaglia G, Bruno V, Bosco P, Carbonaro V, Giuffrida ML, et al. TGF$\beta 1$ pathway as a new target for neuroprotection in alzheimer's disease. CNS Neurosci Ther. 2011;17(4):237-49.

82. Caruso G, Fresta C, Musso N, Giambirtone M, Grasso M, Spampinato S, et al. Carnosine prevents $A \beta$-induced oxidative stress and inflammation in microglial cells: a key role of TGF- $\beta 1$. Cells. 2019;8(1):64.

83. Torrisi SA, Geraci F, Tropea MR, Grasso M, Caruso G, Fidilio A, et al. Fluoxetine and Vortioxetine reverse depressive-like phenotype and memory deficits induced by $A \beta$ (1-42) oligomers in mice: a key role of transforming growth factor- $\beta 1$. Front Pharmacol. 2019;10:693.

\section{Publisher's Note}

Springer Nature remains neutral with regard to jurisdictional claims in published maps and institutional affiliations.
Ready to submit your research? Choose BMC and benefit from:

- fast, convenient online submission

- thorough peer review by experienced researchers in your field

- rapid publication on acceptance

- support for research data, including large and complex data types

- gold Open Access which fosters wider collaboration and increased citations

- maximum visibility for your research: over $100 \mathrm{M}$ website views per year

At $\mathrm{BMC}$, research is always in progress.

Learn more biomedcentral.com/submissions 